\title{
REVIEWS
}

\section{DEVELOPMENTAL DYSLEXIA: GENETIC DISSECTION OF A COMPLEX COGNITIVE TRAIT}

\begin{abstract}
Simon E. Fisher* and John C. D eFries ${ }^{\ddagger}$
Developmental dyslexia, a specific impairment of reading ability despite adequate intelligence and educational opportunity, is one of the most frequent childhood disorders. Since the first documented cases at the beginning of the last century, it has become increasingly apparent that the reading problems of people with dyslexia form part of a heritable neurobiological syndrome. As for most cognitive and behavioural traits, phenotypic definition is fraught with difficulties and the genetic basis is complex, making the isolation of genetic risk factors a formidable challenge. Against such a background, it is notable that several recent studies have reported the localization of genes that influence dyslexia and other language-related traits. These investigations exploit novel research approaches that are relevant to many areas of human neurogenetics.
\end{abstract}

PHONEMES

Individual units of speech sound that combineto make words.
*WellcomeTrust Centrefor Human Genetics, University of Oxford, Roosevelt D rive, Oxford OX3 7BN, UK. ¥Institutefor Behavioral Genetics, University of Colorado, Boulder, Colorado 80309-0447, USA.

Correspondenceto S.E.F. e-mail: simon.fisher@ well.ox.ac.uk doi:10.1038/nrn936
The current perception of dyslexia as a neurological syndrome with a constitutional basis dates back to the original reports, in the mid-1890s, of what was then referred to as 'congenital word blindness' 1,2 . These initial accounts viewed the disorder as the developmental analogue of acquired loss of reading ability; it was already known that neurological damage to certain areas of the brain in adults could result in selective impairment in reading and writing (alexia). Asimplied by the use of terms such as 'word blindness' and 'strephosymbolia' (meaning 'twisted symbols'), early explanations of dysl exia posited that a basic deficit in visual processing was at the heart of the reading difficulties of the affected subjects ${ }^{3}$. Such theories proposed that unstable visual representations lead to errors of letter reversal (such as ' $d$ ' substituted for ' $b$ ') and transposition (such as 'god' instead of 'dog'). It is now widely accepted that dyslexia (also known as'specific reading disability') is better characterized as a language-related condition in which reading problems stem largely from an impairment in the representation and manipulation of PHONEMES ${ }^{4}$. However, there remains a lack of consensus about the exact nature of the putative'core deficit'; indeed, some researchers doubt that there can be an adequate explanation of aetiology in terms of a single underlying process. For example, the 'double-deficit' hypothesis proposes that dyslexia results from the combined effects of two independent deficits, one involving processing of phonemes, the other involving rapid naming of simple visual stimuli (colours, objects, digits or letters) ${ }^{5}$. An important criticism of pure phonological-deficit models of reading disability is that they cannot account for the full range of symptoms that are experienced by people with dyslexia. These include slight but demonstrable impairments in visual ${ }^{6}$ and auditory ${ }^{7}$ perception, and problems with motor coordination ${ }^{8}$. In recent years, several alternative theories have been formulated to explain this complex phenotypic profile, some of which invoke deficits in basic neuronal mechanisms that have an impact on multiple brain modalities ${ }^{6-10}$ (BOX 1).

So, despite decades of comprehensive multidisciplinary investigation, including studies of neuropsychology, brain anatomy, neuroimaging and magnetoencephalography (reviewed extensively elsewhere ${ }^{11}$ ), the specific causal mechanisms that underlie developmental dyslexia are still obscure. Here, we will focus on a rapidly growing area of dyslexia research that 
MENDELIAN

A trait resulting from changes

in a singlegenethat has a

significant effect on the

phenotypeand is inherited in a

simple pattern that is similar or

identical to those described by

Gregor Mendel. Also referred to

asmonogenic.

PROBAND

Usually, the person who serves as thestarting point of a genetic study.

MONOZYGOTIC

Twins that develop from a single fertilized egg cell through its division into two genetically identical parts.

DIZYGOTIC

Twins that develop during the same pregnancy as the result of two separate eggs being fertilized by two separatesperm.

HERITABILITY

Theproportion of variability in a particular characteristic that can beattributed to genetic influences. Thisis a statistical description that applies to a specific population and might changeif theenvironment is altered.

SPECIFIC LANGUAGE IM PAIRMENT

A significant deficit in language development in children with normal non-verbal intelligence that cannot beattributed to hearing loss, inadequate educational opportunity or obviousneurological impairment.

ATTENTION-DEFICIT/ HYPERACTIVITY DISORDER A common disorder with childhood onset, in which persistent inattention and/or hyperactive-impulsive behaviour leads to impaired social and/or academic functioning.

CANDIDATE GENE A genethat encodes a protein the expected or known function of which indicates that it migh beresponsiblefor a disease or trait in a population of individuals. Pure candidate-gene approaches do not exploit or requireinformation on chromosomal location (in contrast to 'positional cloning').

\section{Box 1 | The neurological basis of dyslexia - is there a single underlying cause?}

Initial explanations of 'congenital word-blindness' held that significant defects in the visual system were solely responsible for the letter and word reversals that were believed to epitomize dyslexic reading. This viewpoint turned out to be untenable. Although subtleabnormalities in specific aspects of visual processing have been shown in people with dyslexia ${ }^{6}$, these are unlikely to cause reading problems directly. 0 ver the years, evidence has accumulated to implicate language processing. When learning to read, we develop an explicit understanding that words can be broken down into constituent phonemes, which map to visually presented letter strings, known as graphemes. Phonological-deficit theories, which have dominated the field for someyears, view dyslexia as a cognitivedifficulty in processing phonemest. There is indeed robust evidence that phonological skills of individuals with dyslexia are compromised, but how does this fit with the complexity of the phenotype, which includes an array of subtlesensory impairments and motor difficulties? Several differing (but related) models endeavour to tacklethis thorny issue. For example, rapid-processing hypotheses propose that dyslexia arises from a basic deficit in processing rapidly successive and transient stimuli that enter the nervous system, affecting all modalities ${ }^{10}$. In such models, the phonological impairments that are responsible for reading difficulties stem from a lower-level inability to discriminate acoustic cuesthat are involved in distinguishing phonemes ${ }^{7}$. Themagnocellular deficit theory is based on data from anatomical, psychophysical and imaging studies, which indicate that many people with dyslexia have mild anomalies in the magnocellular visual subsystem ${ }^{6}$. Magnocells are neurons concerned with motion perception and temporal resolution, and areimportant for the control of eye movements. Magnocellular pathways might exist in other sensory modalities, 50 a multi-modal magnocell deficit might account for the full range of symptoms that are associated with dyslexia, with reading difficulties resulting from a combination of visual and phonological impairment ${ }^{9}$. More recently, it has been suggested that dyslexia representsa general impairment in skill automatization that results from cerebellar dysfunction ${ }^{8}$. The debate continues.

might offer a new route to elucidating the aetiology of the syndrome - the field of molecular genetics. This field has already proved to beenormously powerful in isolating causal mechanisms for numerous simple MENDELIAN disorders, and is now being applied to common, complex traits such as heart disease, diabetes, psychiatric disorders and specific learning disabilities. As we describe below, this is an exciting time for research into the genetics of dyslexia. Converging advances in phenotypic dissection, high-throughput genetic analyses and statistical methodologies havegreatly improved our prospects of pinpointing genes that areinvolved in this and other language- related traits. We will discuss how such developments havecontributed to recent successes in the field, but also highlight the limitations and assess the future potential of the molecular genetic approach for studying dyslexia.

\section{Reading deficits are heritable}

Soon after the publication of the original case studies of dyslexia at the turn of the last century, several reports noted that the condition tends to run in families ${ }^{12,13}$. The first large-scale family study ${ }^{14}$ was carried out in 1950; since then, many systematic investigation s have documented an increased risk of reading and spelling problems in the relatives of PROBANDS with dyslexia ${ }^{15-19}$. Familial clustering of a trait is consistent with the involvement of genetic factors, but could also be accounted for by environmental influences that are common to subjectswithin a family. The relative contributions of genetic influences and shared family environment can bedissected in twin studies. It has been shown robustly that concordance for a qualitative diagnosis of dyslexia is significantly higher in MONOZYGOTIC (MZ) twins, who havea virtually identical genetic makeup, than it is in DIZYGoTIC (DZ) twins, who (like ordinary siblings) share about half of their segregating alleles ${ }^{20-22}$. A large-scale study of twins with dyslexia yielded a concordance rate of $68 \%$ in M Z twins, as compared with $38 \%$ in DZ twins, indicating a substantial genetic component ${ }^{23}$. However, there can beintrinsic drawbacks to genetic studies of complex cognitivetraits if thestudies are based on all-or-none definitions of affection status. Qualitative diagnoses of dyslexia are often derived from a subject's scores on quantitative reading-related measures, which vary continuously throughout the general population (BOX 2). As such, therehas been debateover whether dyslexia represents a discrete clinical entity, or simply corresponds to the extremelower tail of normal variability in reading ability ${ }^{24}$.

As an alternative to using dichotomous definitions of dyslexia, somegenetic studies have adopted techniques that involve the direct analysis of continuous indices of severity. DeFries and Fulker developed a method (DeFries-Fulker regression) that exploits twin data to evaluatethe HERITABILITY of extreme deficits in a measure of interest ${ }^{25}$. This is referred to as 'group heritability' $\left(o r \mathrm{~h}^{2}\right.$ ) to distinguish it from estimates of heritability for individual variation in the normal range of ability. The basic D eFries-Fulker technique targets one end of the distribution and involves the selection of twin pairsin which at least onemember has an extremescore (that is, cases in which at least one twin performs very poorly on a continuous measure of reading ability). A statistical test is then used to assess whether the scores of co-twins regress towards the unselected population mean as a function of zygosity ( $D Z$ versus $M Z$ ). If $D Z$ co-twins are more similar to the general population than $M Z$ co-twins, then this points to a rolefor genetic factors. Direct estimates of $\mathrm{h}^{2}$ can be derived from such analyses. For example, in a large set of twin pairs with reading difficulties from Colorado, $\mathrm{h}_{\mathrm{g}}$ was estimated to be $\sim 50 \%$ for a composite score of overall reading performance ${ }^{26}$. The DeFries-Fulker regression method has had a wide impact on the field of childhood learning disorders, having been used to assess the heritability of 
POLYMORPHIC GENETIC MARKERS

Naturally occurring variants in DNA sequencethat can be used to track the inheritance pattern of a particular chromosomal location.

POSITIONAL CLONING A strategy for theidentification of disease genes on the basis of marker inheritance data from affected families that does not require any prior knowledge of theunderlying biological pathways or genefunction (in contrast to 'candidate-gene' approaches). In recent years, a blend of positional cloning and candidate-geneapproaches (sometimes referred to as a 'positional-candidate' strategy) has often been used, involving the combined use of data on map location and expected gene function.

GENOTYPE

The genetic constitution of an individual. This can refer to the entire complement of genetic material or to a specific gene (or set of genes).

\section{PHENOTYPE}

The appearance of an individua in terms of a particular characteristic (physical, biochemical, physiological and so on), resulting from interactions between the individual's genotypeand the environment.

\section{PENETRANCE}

The probability that an individual with a particular genotypemanifestsa given phenotype. Complete penetrance corresponds to the situation in which every individual with thesamespecific genotypemanifests the phenotypein question.

PHENOCOPIES

Peoplewho manifest the same phenotypeas other individuals of a particular genotype, but do not possess this genotype themselves. For example, this might occur when environmental influencesalone evoke a developmental trait that has a similar genetic counterpart.

OLIGOGENICITY When a few different genes work together to contribute to a particular phenotype psychometric measuresin dyslexia ${ }^{27}$, SPECIFIC LANGUAGE IMPAIRMENT ${ }^{28}$ and ATTENTION-DEFICIT/HYPERACTIVITY DISORDER $(A D H D)^{29}$. M oreover, such quantitative approaches, including an extension of DeFries-Fulker regression, have allowed key advances in the genetic mapping of reading disability and other language-related traits.

\section{Genetics of dyslexia - a complex problem}

In the absence of a solid understanding of the mechanisms that underlie dyslexia, there is no a priori reason to expect that any particular gene of known function will be a risk factor. A few theoretical accounts of trait aetiology might indicate possible subsets of genes that could be targeted for study (such as the controversial immune-disorder hypothesis that wediscuss below). However, in general, there are no compelling cases that would sufficiently limit the genetic search to make a pure CANDIDATE GENE approach cost-effective. An alternative strategy is to track the inheritance of different chromosomal regions in familiesthat segregate dyslexia, to map thelocation of putativegenetic risk factors. Thistechnique(linkage mapping) assesses whether POLYM ORPHIC GENETIC MARKERS in particular genomic regions are 'linked' to the trait of interest. Sufficient reliable linkage data might highlight small areas of the genomethat contain a manageable subset of genes. Further investigation of such genes should then allow the identification of specific gene variants in those regions that are involved in trait susceptibility. In the past 25 years, POSITIONAL CLONING has become an extremely fruitful research strategy for the investigation of monogenic disorders, exploiting the simpleinheritance patterns that are observed for such traits.

With a few rare exceptions, the transmission of dyslexia and other language-related traits in affected families tends to be complex; there is no straightforward correspondence between a subject's genetic makeup (GENOTYPE) and his or her cognitive abilities (PHENOTYPE) ${ }^{30,31}$. For example, a family might contain oneor moreindividuals who inherit a high-risk genotype but do not develop problems (cases of incomplete PENETRANCE). Conversely, there might besubjects who are clearly affected, even though they have a low-risk genotype (phenocopies). Genotype-phenotype concordance is further eroded by heterogeneity - distinct genetic loci implicated in different families - and OLIGOGENICITY - allelic variants at multiple loci contributing to increased risk. In combination, these factors severely limit the POWER of traditional linkagemapping, which assumes single-gene inheritanceand relies on the precise specification of transmission pattern, penetrance levels and phenocopy rates.

The problems that are associated with genetic complexity are further compounded by constraints at the phenotypic level. Delineation of the dyslexia phenotype for genetic studies is restricted by a lack of consensus as to the physiological, behavioural and cognitive correlates of the disorder ${ }^{30}$. As a consequence, different investigations into genetic aetiology have generally used distinct diagnostic tools and classification criteria. Sometimes, this is the inevitable outcome of language differences; although most genetic linkage studies have involved English-speaking cohorts ${ }^{32-37}$, investigations have also been conducted in Danish ${ }^{38}$, German ${ }^{39,40}$, Norwegian ${ }^{41}$ and Finnish ${ }^{42}$ families. But regardless of the nativelanguage, operational definitions of dyslexia have varied markedly, yiel ding increased heterogeneity. This could raisequestions when trying to interpret and integrate data from multiplestudies. For example, subjects that have 'phonological coding dyslexia' in one study sampl $\mathrm{e}^{36}$ might not be directly comparable to those reported to have'spelling disability' 40 or 'reading/writing disability associated with severe speech delay' 39 in others.

\section{Box 2 | Defining dyslexia for genetic studies}

What is dyslexia? A standard answer would besomething like "dyslexia is a specific, significant impairment in reading ability that is not explained by deficits in general intelligence, opportunity, motivation or sensory acuity". The deceptive simplicity of this definition breaks down as soon as oneexamines it in detail. How do we decide what constitutes 'specific, significant' impairment in a subject's reading? What level of intellectual deficit would beconsidered adequate to 'explain' poor literacy? D o subtle abnormalities in auditory or visual processing that are only detectable in experimental situations (BOX 1) represent deficits in 'sensory acuity' that would invalidate a positive diagnosis?

Clinical diagnoses of dyslexia usually derive from applying thresholds to psychometric measures that are normally distributed in unselected populations. A commonly used definition requires'significant' (say, - 2 standard deviations) discrepancy between observed reading ability (assessed by standardized word-recognition tests) and that expected on the basis of $I Q^{84}$. The cogency of diagnosis on the basis of $I Q$ - achievement discrepancy has been challenged. For example, the measured IQ of dyslexic children declines with age, and is closely related to socioeconomic status, so that children who are older or of lower socioeconomic status are less likely to be diagnosed by discrepancy criteria ${ }^{85}$. Alternative methods that makeno assumptions about IQ-achievement relationships, such as those requiringa significant lag in reading age ${ }^{86}$, are also flawed. A shortcoming of most classification schemes is the use of thresholds, which are established in an arbitrary manner; thequestion of whether dyslexia is a pathological condition or represents the tail of a normal curve remains unresolved ${ }^{24,87}$. Furthermore, psychometric profiles can vary greatly among people with dyslexia and at different developmental stages. Adolescents and adults with dyslexia can 'compensate'; they seem to havenormal word-recognition skills, but the underlying deficits persist. These deficits can be shown with appropriate tests, such as those that tap spelling, reading rate or phonological skills ${ }^{88}$. Therefore, the choice of diagnostic measure can becrucial. In many situations, clinical all-or-nonediagnoses of dyslexia might not beoptimal for genetic research, as they do not capture the complex essence of the phenotype ${ }^{30}$. 


\begin{tabular}{|c|c|c|c|}
\hline Method & Phenotype & Sample & Advantages \\
\hline $\begin{array}{l}\text { Traditional } \\
\text { parametric } \\
\text { (model based) }\end{array}$ & Qualitative & $\begin{array}{l}\text { Extended families } \\
\text { with multiple } \\
\text { affected members }\end{array}$ & $\begin{array}{l}\text { Most powerful method for detecting } \\
\text { linkage in pedigrees with simple } \\
\text { inheritance, if genetic model is } \\
\text { correctly specified }\end{array}$ \\
\hline
\end{tabular}

\begin{tabular}{|c|c|c|c|}
\hline $\begin{array}{l}\text { Allele-sharing } \\
\text { nonparametric } \\
\text { (model free) }\end{array}$ & Qualitative & $\begin{array}{l}\text { Extended or } \\
\text { nuclear families } \\
\text { with multiple } \\
\text { affected members }\end{array}$ & $\begin{array}{l}\text { No assumptions about mode of } \\
\text { inheritance, penetrance, phenocop } \\
\text { etc.; nuclear families easy to collect }\end{array}$ \\
\hline $\begin{array}{l}\text { Basic } \\
\text { Haseman- } \\
\text { Elston } \\
\text { regression }\end{array}$ & Quantitative & $\begin{array}{l}\text { Phenotyped } \\
\text { sib-pairs }\end{array}$ & $\begin{array}{l}\text { No assumptions about mode of } \\
\text { inheritance etc.; sample easy to } \\
\text { collect; exploits continuous nature } \\
\text { of trait; simple to implement }\end{array}$ \\
\hline $\begin{array}{l}\text { DeFries- } \\
\text { Fulker } \\
\text { regression }\end{array}$ & Quantitative & $\begin{array}{l}\text { Phenotyped } \\
\text { sib-pairs; extreme } \\
\text { proband }\end{array}$ & $\begin{array}{l}\text { No assumptions about mode of } \\
\text { inheritance etc.; sample easy to } \\
\text { collect; exploits continuous nature } \\
\text { of trait; simple to implement; well } \\
\text { suited to selected samples }\end{array}$ \\
\hline $\begin{array}{l}\text { Variance- } \\
\text { components } \\
\text { partitioning }\end{array}$ & Quantitative & $\begin{array}{l}\text { Phenotyped } \\
\text { sib-pairs or } \\
\text { extended families }\end{array}$ & $\begin{array}{l}\text { No assumptions about mode of } \\
\text { inheritance etc.; sample easy to } \\
\text { collect; exploits most of observed } \\
\text { variability in trait; incorporates all } \\
\text { pedigree members simultaneously }\end{array}$ \\
\hline
\end{tabular}

\section{Disadvantages}

Depends on accurate specification of mode of inheritance, penetrance, phenocopy etc.; assumes monogenic transmission; large families with simple inheritance patterns are rare; can be limited by dichotomous classification of complex trait

Large sample sizes needed to yield sufficient power; some methods sensitive to

specification of allele frequencies; can be limited by dichotomous classification of complex trait

Large sample sizes needed to yield sufficient power; does not exploit all available trait variability; difficult to accommodate multiple sib-ships

Large sample sizes needed to yield sufficient $33,34,50-52$ power; does not exploit all available trait variability; difficult to accommodate multiple sib-ships; no a priori basis for choosing leve of selection

Large sample sizes needed to yield sufficient power; computationally intense; tests of significance assume multivariate normality
References*

$32,41,42$

$35,40-42$

37,63

*Key examples of dyslexia linkage studies that have successfully applied each of these methods. Note that the terms 'nonparametric' or 'model free' are not entirely accurate; although such approaches do not depend on the previous specification of penetrance, phenocopy or transmission, they do sometimes involve the estimation of certain parameters and/or rely on various assumptions about the genetic model. Nevertheless, nonparametric/model-free methods are much less restrictive than the fully parametric approach.

POWER

The probability of correctly rejecting thenull hypothesis when it istruly false. For linkage studies, the null hypothesis is that of 'no linkage', so the power represents the probability of correctly detecting a genuine linkage.

QUANTITATIVE TRAIT LOCUS (QTL). A genetic locus or chromosomal region that contributes to variability in a complex quantitative trait (such as body weight), as identified by statistical analysis.
This leads us to another area of controversy. Is dyslexia a single trait or a cluster of related subtypes with distinct aetiologies (which arelikely to involve different subsets of genes)? Castles and Coltheart proposed the existence of two forms of dyslexia that are analogous to subtypes that wereformerly documented in alexia cases ${ }^{43}$. They based their classification scheme on the idea that skilled readers can use two discrete routes for decoding text, one involving processing of theindividual phonemes that make up a word, and the other exploiting direct recognition of whole-word letter patterns (orthography) without apparent need for phonological mediation. Psychometric testing of children with dyslexia identified some individuals who seemed to have sel ective deficits in either the phonological or the orthographic route. Castles and Coltheart defined these as cases of phonological and surface dyslexia, respectively ${ }^{43}$. Although the underlying assumption of a'dual-route' reading model has been criticized, twin studies of phonological and surface subgroups have indicated greater heritability of reading defi cits for the former, whereas shared environment is important for the latter ${ }^{44}$, supporting the idea of divergent aetiologies. But although a significant number of poor readers fit the characteristics of either proposed subtype, most cases have difficulty with both phonological and orthographic tasks (as discussed further below).

A final problem for phenotypic definition is that the nature and severity of deficits might vary at different developmental stages of the life of the person with dyslexia. This troublesomeissue is usually disregarded by molecular studies (BOX 2). It could beaddressed in the future by obtaining longitudinal data at multipletime points from each subject in a study.

\section{Mapping genes for dyslexia}

In recent years, innovations in three areas have contributed to success in localizing genes for dyslexia and other language related traits. These are QuANTITATIVE TRAIT Locus (QTL) mapping, phenotypic dissection and highthroughput genome-widescanning. Most current linkage studies of dyslexia use one or more of these to facilitate genemapping.

QTL mapping. As discussed above, analyses of continuous indices of severity in twins have been important for assessing genetic contributions to reading and language deficits $21,22,27,28$. Direct use of the same quantitative measuresin combination with molecular genetic data provides a strategy for localizing potential risk factors to particular chromosomal regions. QTL mapping is one form of what are often referred to as 'nonparametric' or 'model-free' linkage methods (TABLE 1). Thesetend to be moresuitablefor complex genetic traits than 'parametric' linkage methods, as they do not rely on assumptions of monogenic inheritance, estimates of penetrancelevels, phenocopy rates and gene frequencies, or the precise specification of transmission (recessive, dominant, sexlinked and so on) ${ }^{45}$. Furthermore, they can better handle unknown levels of heterogeneity and oligogenicity. The trade-off for nonparametric techniques is that they usually require very largedata sets (several hundred nuclear families) to yield sufficient power for genemapping ${ }^{45}$. 
Sharing 0 alleles IBD

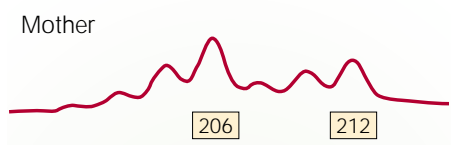

Father

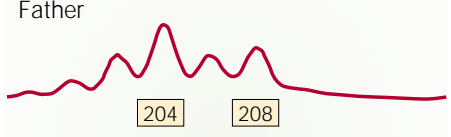

Sibling 1

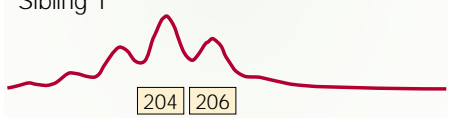

Sibling 2

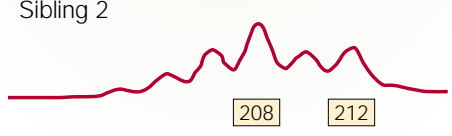

Sharing 1 allele IBD

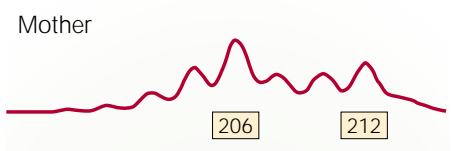

Father

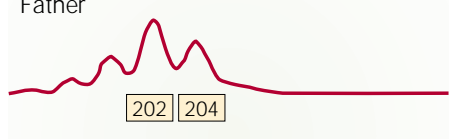

Sibling 1

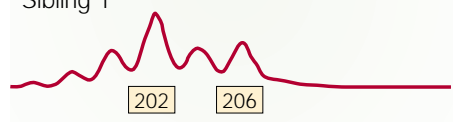

Sibling 2

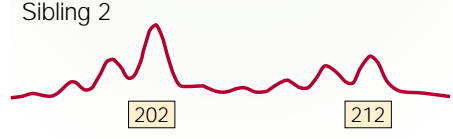

Sharing 2 alleles IBD

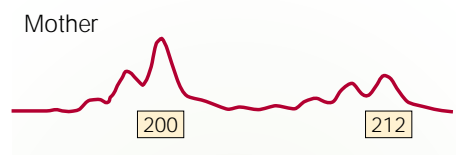

Father

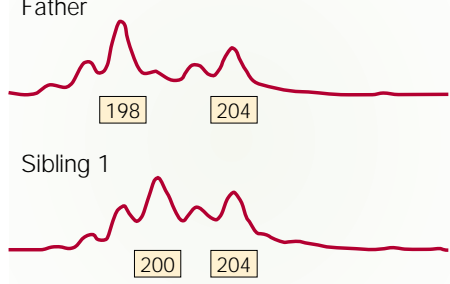

Sibling 2

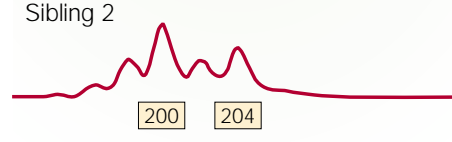

Figure 1 | IBD allele sharing can be assessed using polymorphic genetic markers. Examples of genotype data from three nuclear families, showing the three types of identical-by-descent (IBD) allele sharing (0, 1 or 2). Genotypes such as these are generated using high-throughput fluorescence-based genotyping technology ${ }^{56}$. Numbers in boxes underneath the peaks correspond to sizes (in base pairs) of the alleles, automatically called by genotyping software. IBD estimates derived from such genotype data are subsequently used for linkage analysis. Adapted, with permission, from REF. 56 @ 1999 Steinkopff Verlag.

Typically, such methods rely on estimating whether related subjects have inherited identical copies of a polymorphic genetic marker from a common ancestor (FIG. 1). For example, at any particular marker, a pair of siblings will share, on average, $50 \%$ of their alleles identical-by-descent (IBD), owing to random segregation. Qualitative nonparametric approaches test whether a chromosomal region shows elevated IBD allele sharing in related subjects who are concordant for a disorder. H owever, they retain one potential limitation of other qualitative approaches in adopting allor-none classifications of affection status. Quantitative nonparametric approaches (QTL methods) evaluate whether there is a significant correlation between genetic similarity (indexed by IBD allelesharing) and phenotypic resemblance (assessed through a comparison of quantitative scores) for related peoplein the chromosomal region of interest. As they directly exploit additional phenotypic information that is available from quantitative data, QTL approaches often have advantages over qualitative nonparametric approaches, assuming that the measures are reliable and accurate indices of severity ${ }^{30,31}$. H owever, as outlined in TABLE 1, the alternative strategies that are available for phenotypic definition and statistical analysis might have different strengths and weaknesses depending on the nature of the study sample.

Simple implementations of QTL mapping use regression analysis in sib-pairs to assess phenotypegenotype relationships (FIG. 2). The original HasemanElston method regresses the square of the difference in siblings' phenotypic scores against the number of alleles shared IBD at a particular marker ${ }^{46}$. Alternatively, an extension of DeFries-Fulker regression is ideal for investigating samples selected from one tail of a normal distribution, which can offer increased power for detecting genetic effects. The DeFries-Fulker linkage method assesses whether co-sibs of individuals with extreme phenotypic scores regress towards the unselected population mean as a function of IBD at the marker under investigation ${ }^{47}$. Regression-based methods arestraightforward to apply (t-tests of appropriate regression coefficients yield estimates for significance of linkage), but they do not exploit all the available trait information. M oreover, there is disagreement over how best to accommodate nuclear families that contain multiplesib-ships, in which alternative pairings of sibs are not fully independent, or more complex extended pedigrees.

A complementary approach that is based on variance components simultaneously evaluates all relationships in a family and makes use of almost all observed phenotypic variability, but is computationally intense $\mathrm{e}^{48}$. Trait variability is partitioned into components due to major-gene, unlinked POLYGENIC and residual environmental factors, using maximum-likelihood estimation. To assess linkage, thelikelihood of the data under the null hypothesis (no major-gene effect) is compared with that when the major-genecomponent is unconstrained (FIG. 2). Nominal estimates of significance, which are derived from likelihood-ratio tests, are based on an assumption of multivariate normality. This is likely to beinvalid for many data sets, particularly selected samples, and might lead to false-positive evidence for linkage(increased type-I error) or reduced power to detect a real effect (increased type-ll error) ${ }^{49}$. Various options exist for surmounting this problem, including the use of simulations to derive empirical-based estimates of significance $^{50}$. H aseman-Elston, D eFries-Fulker and variance-components methods have been used successfully to localize putative dyslexia risk factors, such as that on chromosome $6 p$ (REFS 33,34,37,50,51). 


\section{GRAPHEME}

A written symbol, or group of

symbols, that is used to represent

a specific phoneme

MULTIPOINT ANALYSIS

Theuse of data obtained from multipleneighbouring genetic markers on the same chromosome to extract linkage information at many points across a genomic region.

SINGLE-POINT ANALYSIS Theinvestigation of linkageat one point on a chromosome, using data from a singlemarker.

\section{LOD SCORE}

Linkagemapping involves comparing two likelihoods. The first is thelikelihood of the data under the hypothesis that there is linkage between inheritance of thetrait and that of the chromosomal region in question. The second is the likelihood of the data, under the null hypothesis that thereis no linkage. Thelod scoreis the logarithm of thelikelihood ratio; if it exceeds a given threshold, thenull hypothesis can be rejected.
Phenotypic dissection. M any genetic studies of dyslexia have focused on what might be referred to as 'global' deficit (see BOX 2), using general diagnoses or quantitative analyses of overall indices of severity (for example, on the basis of scores on standardized tests of word recognition or spelling ability). Recently, there has been a move towards complementary approaches in which the dyslexia profile is dissected into distinct but related phenotypic components $\mathrm{s}^{35,37,50-52}$. This dissection is driven by theories about the nature of the reading process, but the validity of using such hypothetical components is well supported by cognitive-psychological and psychometric studies. Tests have been developed that are believed to tap predominantly each putative component. For example, phoneme awareness, defined as the capacity to reflect explicitly on the individual elements of speech, can beassessed with oral tasks that do not involve the visual processing of print. These might include tests requiring phoneme deletion ${ }^{51}$ ("say 'prot' without the 'r' sound" - 'pot') or the construction of 'spoonerisms'50 ("swap around the first sounds of these two words: 'cat sad'" - 'sat cad'). Phonological decoding, the ability to convert written GRAPHEME units into their corresponding phonemes, is usually evaluated through oral reading of pronounceable words that lack real meaning (non-words), such as 'teg' or 'latsar'43. Recognition of whole-word orthography (orthographic coding) can be measured through the oral reading of words that violate standard letter-sound conventions of English, such as 'meringue' and 'yacht'. These irregular words cannot be read correctly using phonemegrapheme conversion rules, so success should principally reflect orthographic-processing ability ${ }^{43}$. Orthographic skills can also be assessed using forced-choice tasks that require rapid recognition of a correctly spelt target word versus a phonologically identical nonword ('rain' versus'rane') ${ }^{51}$. Another ability that seems to beimpaired in many peoplewith dyslexia involves the rapid serial naming of visual stimuli (rapid automized naming) $)^{5,35,52}$.

The relationship between hypothetical components and their relative importance for reading and spelling problems in dyslexia remains an active area of study ${ }^{27,52-55}$. Twin studies indicate that group deficits in quantitative measures of phonological, orthographic and rapid-naming skills of people with dyslexia are all significantly heritable $\mathrm{e}^{27,52}$. It is important to realize that the components are overlapping, not independent; inter-trait correlations between reading- and language-related measures are usually moderate to high ${ }^{27,55}$. Furthermore, analysis with a bivariate extension of the DeFries-Fulker regression indicates that a substantial proportion of the observed covariance is due to genetic factors that are common to all components ${ }^{27,52}$. However, such investigations also indicate the existence of genetic effects that uniquely influence theindependent variance of different measures (for example, phonological versus orthographic) ${ }^{27}$. There might even be distinct genetic influences acting on accuracy and latency deficits that can be observed for the same component ${ }^{27}$. a

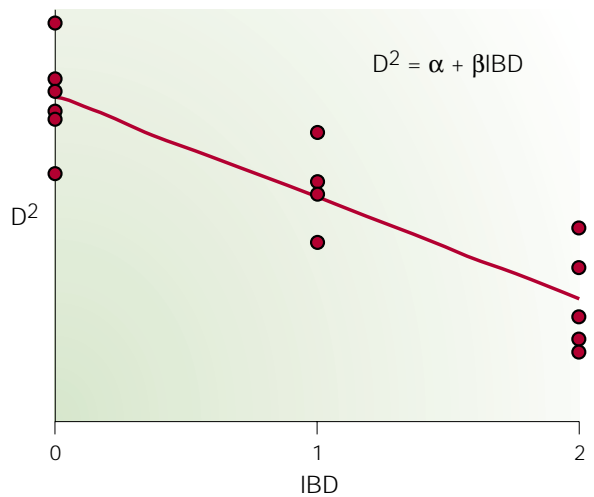

b

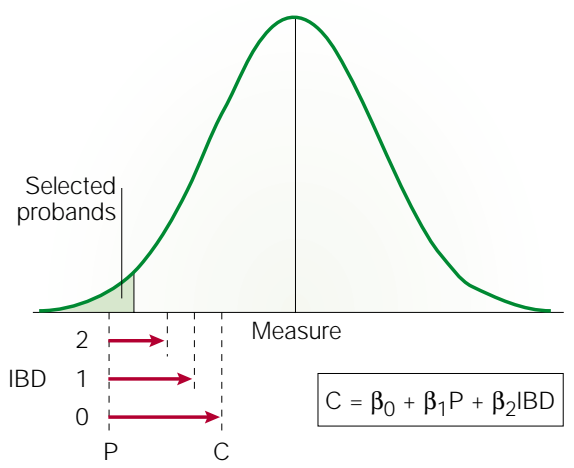

C

\begin{tabular}{lllll} 
& \multicolumn{3}{c}{} & \multicolumn{2}{c}{ Total variance } & \multicolumn{2}{c}{\begin{tabular}{l} 
Log \\
\cline { 2 - 4 }
\end{tabular}} & $\begin{array}{l}\text { Major gene } \\
\text { Polygenic }\end{array}$ & Environment likelihood \\
$\begin{array}{l}\text { Null } \\
\text { hypothesis }\end{array}$ & 0.00 & 0.62 & 0.38 & $L(0)$ \\
$\begin{array}{l}\text { Unlinked } \\
\text { locus* }\end{array}$ & 0.00 & 0.62 & 0.38 & $L(A)$ \\
$\begin{array}{l}\text { Linked } \\
\text { locus* }\end{array}$ & 0.33 & 0.29 & 0.38 & $L(A)$ \\
\hline
\end{tabular}

*Alternative hypothesis

Chi-square $=-2 \times(L(0)-L(A))$

Figure 2 | Methods for QTL-based linkage mapping in humans. a |The basic Haseman-Elston method evaluates the relationship between differences in siblings' scores (D) and their identical-by-descent (BBD) allele status. A t-test of regression coefficient $\beta$ yields an estimate of significance ${ }^{46}$. $\mathbf{b} \mid$ DeFriesFulker regression requires the selection of 'probands' $(\mathrm{P})$, followed by an assessment of whether co-sibs $(C)$ regress further towards the unselected mean as IBD status decreases. A t-test of regression coefficient $\beta_{2}$ yields an estimate of significance ${ }^{47}$. c | Variance-components analysis involves partitioning the total variability into major-gene, polygenic and environmental factors ${ }^{48}$. Under the null hypothesis, the likelihood of the data is maximized, with the major-gene component constrained at 0 . Under the alternative hypothesis, the likelihood of the data is maximized without this constraint. If there is no linkage between trait variability and IBD status at the locus in question, then the major-gene effect under the alternative hypothesis remains $0 . L(0)$ and $L(A)$ are log likelihoods of the data under the null hypothesis and the alternative hypothesis, respectively. Evidence for linkage is assessed by a likelihood-ratio test. This provides a valid test of linkage significance (given certain assumptions ${ }^{49}$ ). However, when analysing the top results from a genome scan, the maximum-likelihood values of the components under linkage are not themselves meaningful and will give biased estimates of effect size ${ }^{78}$. The figures shown here are used simply to illustrate the approach and are not taken from real analyses. 
REVIEWS

\begin{tabular}{|c|c|c|c|c|c|}
\hline Authors (year) & $\begin{array}{l}\text { Families } \\
\text { (country) }\end{array}$ & $\begin{array}{l}\text { Treatment of } \\
\text { phenotype }\end{array}$ & $\begin{array}{l}\text { Linkage } \\
\text { method }\end{array}$ & Summary of findings & Reference \\
\hline Smith et al. (1983) & 9 (USA) & $\begin{array}{l}\text { Qualitative, } \\
\text { global }\end{array}$ & Parametric & $\begin{array}{l}\text { Lod of } 3.24 \text { with marker cen15 (chromosome } 15 \text { centromeric } \\
\text { heteromorphism) }\end{array}$ & 32 \\
\hline Bisgaard et al. (1987) & 5 (Denmark) & $\begin{array}{l}\text { Qualitative, } \\
\text { global }\end{array}$ & Parametric & Exclusion of linkage to cen15 (lod of -3.42) & 38 \\
\hline Smith et al. (1991) & 19 (USA) & $\begin{array}{l}\text { Qualitative, } \\
\text { global } \\
\text { Quantitative, } \\
\text { global }\end{array}$ & $\begin{array}{l}\mathrm{HE*} \\
\mathrm{HE}\end{array}$ & $\begin{array}{l}P=0.009 \text { for RFLP marker ynz90, mapping between } 15 q 15 \\
\text { and 15qter } \\
P=0.03 \text { for RFLP marker ju201, mapping between } 15 q 15 \\
\text { and 15qter }\end{array}$ & 63 \\
\hline Fulker et al. (1991) & 19 (USA) & $\begin{array}{l}\text { Quantitative, } \\
\text { global }\end{array}$ & DF & $P<0.005$ for markers ynz90 and ju201 & 64 \\
\hline Rabin et al. (1993) & 9 (USA) & $\begin{array}{l}\text { Qualitative, } \\
\text { global }\end{array}$ & Parametric & $\begin{array}{l}\text { Exclusion of linkage to multiple RFLP markers in proximal } \\
\text { region of } 15 q\end{array}$ & 62 \\
\hline $\begin{array}{l}\text { Grigorenko et al. } \\
\text { (1997) }\end{array}$ & 6 (USA) & $\begin{array}{l}\text { Qualitative, } \\
\text { components }\end{array}$ & Nonparametric & $\begin{array}{l}\text { Lod of } 3.15 \text { with microsatellite marker D15S143 in } 15 q 21 \text { for } \\
\text { single-word reading; no report of linkage to phoneme } \\
\text { awareness, phonological decoding, rapid automized naming } \\
\text { or IQ-reading discrepancy } \\
\text { Generally negative; a significant result was said to be obtained } \\
\text { for D15S128 in 15q11, but no details were presented }\end{array}$ & 35 \\
\hline $\begin{array}{l}\text { Schulte-Körne et al. } \\
\text { (1998) }\end{array}$ & 7 (Germany) & $\begin{array}{l}\text { Qualitative, } \\
\text { global }\end{array}$ & $\begin{array}{l}\text { Parametric } \\
\text { Nonparametric }\end{array}$ & $\begin{array}{l}\text { Multipoint analyses gave } P=0.0042 \text { at D15S132 in } 15 q 21 \\
\text { Multipoint analyses gave } P=0.03 \text { at D15S143 }\end{array}$ & 40 \\
\hline
\end{tabular}

All studies initially identified extended families on the basis of multiple affected individuals in different generations, but the subsequent analyses varied in several respects. Qualitative affection status or quantitative measures of deficit were used; most studies adopted a global assessment of the phenotype, whereas one study (that of Grigorenko et al., 1997) dissected the phenotype into hypothetical components. The linkage method was either parametric model-based linkage analysis or nonparametric linkage analysis of allele sharing in affected relatives. DF, DeFries-Fulker regression analysis of selected sib-pairs; HE, Haseman-Elston regression analysis of sib-pairs; RFLP, restriction fragment length polymorphism. *Haseman-Elston analysis can be performed for a qualitative all-or-none diagnosis by treating this as a measure where $0=$ unaffected and $1=$ affected

\author{
CHROMOSOMAL \\ HETEROMORPHISM \\ Natural variation in the shapeor \\ staining pattern of a \\ chromosome, as viewed under \\ themicroscope. \\ CENTROMERE \\ The constricted region of a \\ chromosomethat includes the \\ site of attachment to the mitotic \\ or meiotic spindle. Geneticists \\ divide the chromosomeinto \\ 'short' and 'long' arms, which are \\ separated by this centromere. \\ CENTIM ORGAN \\ A standard measure of genetic \\ distance that is derived from \\ observations of recombination \\ between neighbouring loci. The \\ relationship to actual physical \\ distancealong a chromosome \\ varies throughout the genome; \\ on average, 1 centimorgan \\ corresponds to around one \\ million bases of DNA.
}

Genome-wide scanning. The most thorough way of identifying genetic linkage involves a systematic search of all chromosomes, which requires the analysis of several hundred polymorphic markers in numerous subjects ${ }^{56}$. Using MULTIPOINT methods, it is possibleto infer the IBD status of chromosomal intervals between markers, allowing the assessment of linkage at virtually all points across the genome (in contrast to SINGLE-POINT analyses, which evaluatelinkage at each marker in isolation) ${ }^{57}$. Genome-wide searches used to be prohibitively labour-intensive and time-consuming, beyond the capabilities of many laboratories. After the development of high-throughput genotyping technologies, they now represent a standard tool for the analysis of both monogenic and complex traits ${ }^{56}$. For dyslexia and other language-related traits, genome-widescans have been carried out either in singleextended pedigrees ${ }^{41,42,58}$ or in largesamples of sib-pairs ${ }^{50,59}$. Thesescansinvolve analyses of multipleindependently segregating genomic regions. The concomitant multiple testing results in a substantial increase in the risk of identifying false-positive results (linkageobservations that are dueto chance, rather than real aetiological effects). It is therefore an accepted procedure to adopt stringent thresholds for declaring theidentification of significant linkage. LOD SCORES or $P$-values are the common currencies for describing strength of linkage results. Traditionally, a lod score of 3 is deemed to be 'significant' in parametric analysis of monogenic pedigrees, but it has been argued that a threshold of 3.6 is more suitable for sib-pair allelesharing methods $s^{60}$. This threshold can be shown to correspond to a nominal P-value of 0.00002 , constituting a strict cut-off to guard strongly against false-positive linkages. Note that many genome-wide scans of complex traits do not yield such strong results ${ }^{61}$, and that, even if they do, a proportion of 'significant' linkages will still turn out to be chanceevents, so replication in independent studies remains crucial ${ }^{60}$.

\section{Targeted linkage studies of dyslexia}

Several molecular genetic studies of dyslexia have focused on specific chromosomal regions or have screened a limited proportion of the genome with some success. In 1983, Smith et al. carried out the first linkagestudy of dyslexia, investigating the handful of CHROMOSOMAL HETEROM ORPHISMS and protein polymorphisms that were availableat the time $\mathrm{e}^{32}$. A parametric analysis of extended families with three-generation histories of reading disability yielded significant linkage to the chromosome 15 CENTROMERE, originating mainly from one family (TABLE 2; FIG. 3). Subsequent reports could not support theinitial findings ${ }^{38,62}$. Oneinvestigation re-analysed the family that had given strongest evidence in the original study, but used more highly polymorphic DNA-based markers. Thenew data excluded linkage to the centromere and neighbouring regions of $15 q$ in this and other families ${ }^{62}$. In 1991, Smith and co-workers reported a follow-up to their 1983 study, involving nonparametric analyses of new markers in an expanded sample of kindreds ${ }^{63}$. Although linkage was observed to markers on $15 q$, these mapped $90-120$ CENTIM ORGANS from the original site of interest 63,64 . Grigorenko and colleagues 35 investigated qualitatively defined component phenotypes in extended familiesfor this region. They observed significant linkage with single-word reading at onemarker, D 15S143 in 15q21, when using 


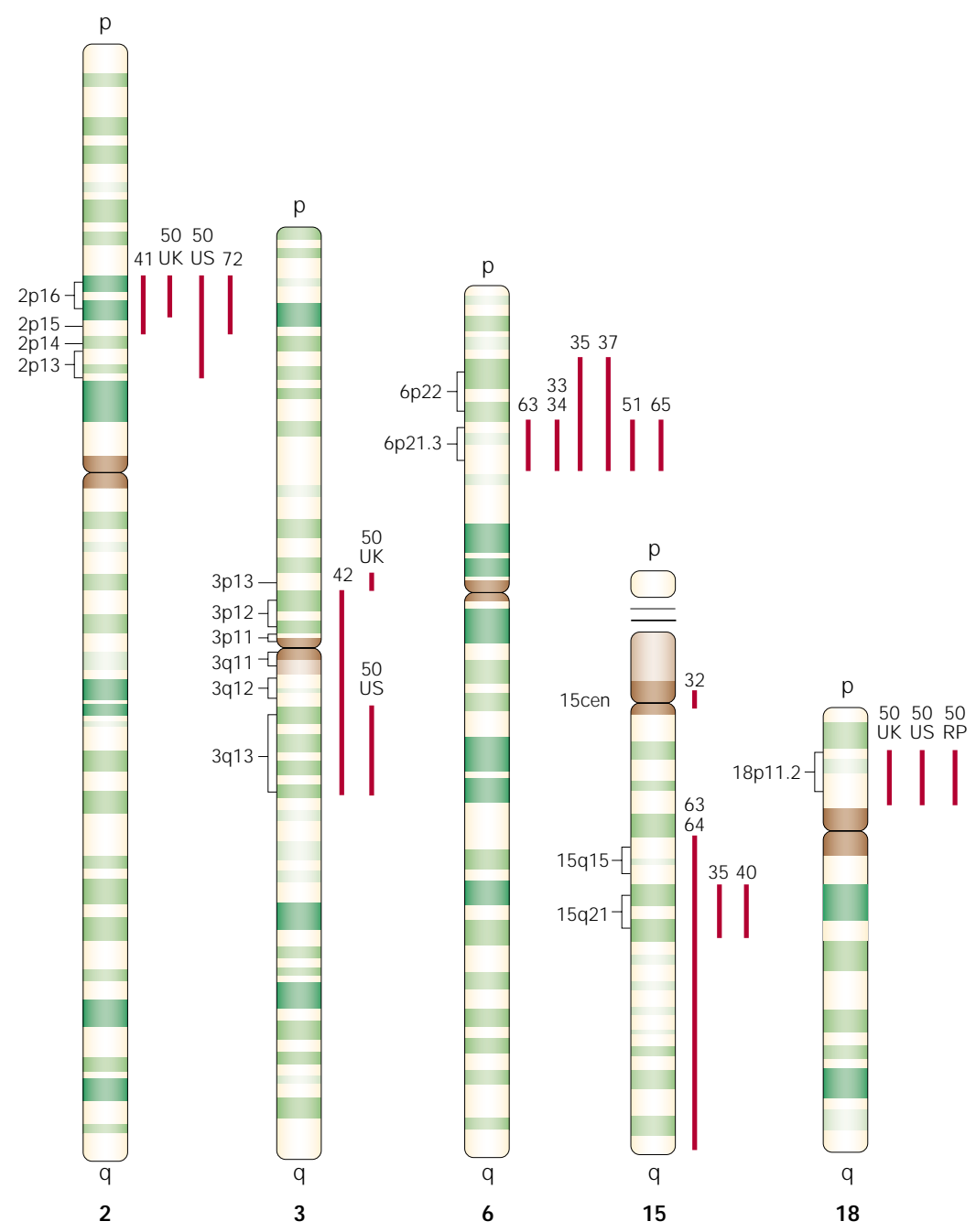

Figure 3 | Replicated regions of chromosomes 2, 3, 6, 15 and 18 implicated by linkage studies of dyslexia. Ideograms of each chromosome are shown with the cytogenetic bands of interest indicated. Each chromosome has a short ( $p$ ) arm and a long (q) arm, which are separated by a centromere. Red bars indicate approximate positions of positive regions of linkage, with the relevant citation number of the study shown above. REF. 50 included two independent genome scans (using samples from the United Kingdom and the United States) and a further replication set (RP). Further details of each study are given in TABLES 2-4 and in the main text. colleagues ${ }^{33,34}$ analysed sib-ships from these kindreds and a sample of DZ twins, using QTL methods and DNA-based markers, thereby obtaining evidence for the 6 p21.3 locus in each data set. Linkage of readingrelated phenotypes to $6 \mathrm{p} 21.3$ has since become one of the most replicable findings in the genetics of human cognition (TABLE 3). Evidence from several independent data sets shows remarkable agreement about the probable position of the risk locus $33-35,37,50-52,65$ (FIG. 3). Samples implicating $6 p$ have been obtained from diverse sources and studied with a variety of methods, including qualitative analyses of extended pedigrees 35,65 and quantitative approaches in sib-pairs or DZ twins ${ }^{33,34,37,50-52}$. These findings areintriguing in view of one often-contested theory of dyslexia aetiology, which posits a direct connection between immune dysfunction and reading problem $s^{66}$. However, data from the same samples that support genetic linkage of readingrelated phenotypes to $6 \mathrm{p} 21.3$ fail to support a connection (mediated genetically or otherwise) between immune disorders and dyslexia ${ }^{67}$. It seems likely that the putative dyslexia risk factor on $6 p$ is not a gene of the immunesystem, and that its location adjacent to a cluster of immune-related genes has no aetiological significance. Although evidence in support of an involvement of $6 \mathrm{p} 21.3$ is more robust than that for $15 q 21$, there have been reports of non-replication in large samples ${ }^{36,40,68}$. Still, these negative studies did not formally excludetheinvolvement of $6 p$. For example, a QTL-based study of Canadian families did not find significant evidence of linkage, probably owing to genetic heterogeneity. But the authors did note that some of their results were weakly supportive, including a lod score of 0.82 in a region that was consistent with the positivestudies ${ }^{68}$.

Targeted studies $62,69,70$ have also led to suggestions of other potential sites of dyslexia linkage on 1p34-36 and $6 q 12$. At present, the data that support these sites are weaker than those for loci on 6 p21.3 and 15q21, so further investigation is required ${ }^{69,70}$.

\section{A genome-wide perspective}

As highlighted here, integrating data from multiple molecular investigations of dyslexia can be problematic, even when similar chromosomal regions seem to be implicated. Theinterpretation of results is complicated by discrepancies in the criteria for sample recruitment, phenotypic definition, marker selection and analytical method. M oreover, most studies have focused on small subsets of the human genome, often analysing the same marker data from these limited regions with several different analytical approaches. Thereare substantial benefits to be gained from obtaining a genome-wide perspective of linkagein any given sample of families ${ }^{56}$. In targeted studies, a locus with an important effect on the phenotype could remain undetected, simply because the relevant chromosomal region was never examined. Furthermore, with genome-wide data, it is possible to assess the general behaviour of linkage statistics in the sample under investigation, allowing a comparison of positive results to background levels of 


\begin{tabular}{|c|c|c|c|c|c|}
\hline Authors (year) & Sample (country) & $\begin{array}{l}\text { Treatment of } \\
\text { phenotype }\end{array}$ & $\begin{array}{l}\text { Linkage } \\
\text { method }\end{array}$ & Summary of findings & References \\
\hline Smith et al. (1991) & $\begin{array}{l}19 \text { extended } \\
\text { families (USA) }\end{array}$ & $\begin{array}{l}\text { Qualitative, } \\
\text { global } \\
\text { Quantitative, } \\
\text { global }\end{array}$ & $\begin{array}{l}\text { HE } \\
H E\end{array}$ & $\begin{array}{l}\mathrm{P}<0.02 \text { with marker GLO1 (a protein polymorphism in the } \\
\text { red cell enzyme glyoxylase } 1 \text { ), mapping to } 6 \mathrm{p} 21.3 \\
\mathrm{P}<0.0001 \text { with marker BF (a protein polymorphism in } \\
\text { properdin factor), which maps to } 6 \mathrm{p} 21.3\end{array}$ & 63 \\
\hline $\begin{array}{l}\text { Cardon et al. } \\
(1994,1995)^{*}\end{array}$ & $\begin{array}{l}19 \text { extended } \\
\text { families (USA) } \\
46 \text { DZ twin } \\
\text { pairs (USA)* }\end{array}$ & $\begin{array}{l}\text { Quantitative, } \\
\text { global } \\
\text { Quantitative, } \\
\text { global }\end{array}$ & $\begin{array}{l}\text { DF } \\
\text { DF }\end{array}$ & $\begin{array}{l}\text { Interval mapping identified peak linkage }(P=0.04) \text { between } \\
\text { DNA markers D6S105 and TNFB in } 6 p 21.3 \\
\text { Interval mapping identified peak linkage }(P=0.009) \text { between } \\
\text { D6S105 and TNFB* }\end{array}$ & 33,34 \\
\hline $\begin{array}{l}\text { Grigorenko et al. } \\
\text { (1997) }\end{array}$ & $\begin{array}{l}6 \text { extended } \\
\text { families (USA) }\end{array}$ & $\begin{array}{l}\text { Qualitative, } \\
\text { components }\end{array}$ & $\begin{array}{l}\text { Parametric } \\
\text { Nonparametric }\end{array}$ & $\begin{array}{l}\text { No significant linkage for any phenotypes examined (phoneme } \\
\text { awareness, phonological decoding, rapid automized naming, } \\
\text { single-word reading or IQ-reading discrepancy) } \\
\text { Multipoint analyses gave } P<0.005 \text { in D6S109-D6S306 } \\
\text { interval of } 6 \text { p } 22.3-21.3 \text { for each phenotype; strongest results } \\
\text { for phoneme awareness ( } P<0.000001) \text {, weakest for single- } \\
\text { word reading }(P<0.005)\end{array}$ & 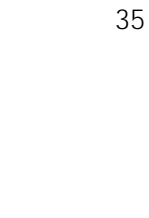 \\
\hline $\begin{array}{l}\text { Schulte-Körne } \\
\text { et al. (1998) }\end{array}$ & $\begin{array}{l}7 \text { extended } \\
\text { families } \\
\text { (Germany) }\end{array}$ & $\begin{array}{l}\text { Qualitative, } \\
\text { global }\end{array}$ & $\begin{array}{l}\text { Parametric } \\
\text { Nonparametric }\end{array}$ & $\begin{array}{l}\text { No significant linkage; multipoint analyses gave lod of }-0.95 \\
\text { between D6S105 and D6S464 in } 6 p 21.3 \\
\text { No significant linkage; multipoint analyses gave } P=0.21 \\
\text { between D6S105 and D6S464 }\end{array}$ & 40 \\
\hline $\begin{array}{l}\text { Field and Kaplan } \\
\text { (1998) }\end{array}$ & $\begin{array}{l}79 \text { families, nuclear } \\
\text { and extended } \\
\text { (Canada) }\end{array}$ & $\begin{array}{l}\text { Qualitative, } \\
\text { global }\end{array}$ & $\begin{array}{l}\text { Parametric and } \\
\text { nonparametric }\end{array}$ & Absence of linkage to several markers in $6 p 23-21.3$ & 36 \\
\hline Fisher et al. (1999) & $\begin{array}{l}82 \text { nuclear families } \\
\text { (UK) }\end{array}$ & $\begin{array}{l}\text { Quantitative, } \\
\text { components }\end{array}$ & VC & $\begin{array}{l}\text { Multipoint analyses identified peak linkage between } \mathrm{D} 6276 \\
\text { and D6S105 in } 6 \mathrm{p} 21.3 \text { for tests of phonological decoding } \\
(P=0.007) \text { and orthographic coding }(P=0.0006) \\
\text { Multipoint analyses identified peak linkage between } D 6276 \\
\text { and D6S105 for phonological decoding }(P=0.004) \text { and } \\
\text { orthographic coding }(P=0.007)\end{array}$ & 37 \\
\hline Gayán et al. (1999) & $\begin{array}{l}79 \text { twin-based } \\
\text { families (USA) }\end{array}$ & $\begin{array}{l}\text { Quantitative, } \\
\text { components }\end{array}$ & DF & $\begin{array}{l}\text { Multipoint analyses identified peak linkage close to D6276 for } \\
\text { several reading- and language-related measures; strongest } \\
\text { results were lods of } 1.46 \text { for phoneme awareness, } 2.42 \text { for } \\
\text { phonological decoding and } 3.1 \text { for orthographic choice }\end{array}$ & 51 \\
\hline $\begin{array}{l}\text { Petryshen et al. } \\
(2000)\end{array}$ & $\begin{array}{l}79 \text { families } \\
\text { (Canada) }\end{array}$ & $\begin{array}{l}\text { Quantitative, } \\
\text { components }\end{array}$ & VC & $\begin{array}{l}\text { No significant linkage with measures of phoneme awareness, } \\
\text { phonological coding, rapid automized naming or spelling; } \\
\text { however, spelling gave } P=0.07 \text { at TNFB } \\
\text { Weak evidence of linkage to } 6 \text { p23- } 21.3 \text { for phonological } \\
\text { coding, rapid automized naming and spelling (spelling gave a } \\
\text { lod of } 0.82 \text { close to TNFB) }\end{array}$ & 68 \\
\hline $\begin{array}{l}\text { Grigorenko et al. } \\
(2000)\end{array}$ & $\begin{array}{l}8 \text { extended } \\
\text { families (USA) }\end{array}$ & $\begin{array}{l}\text { Qualitative, } \\
\text { components }\end{array}$ & Nonparametric & $\begin{array}{l}\text { Support for linkage to D6S464-D6S273 region in } 6 p 21.3 \text { for a } \\
\text { variety of phenotypes, including single-word reading, } \\
\text { vocabulary and spelling }\end{array}$ & 65 \\
\hline
\end{tabular}

Qualitative affection status or quantitative measures of deficit were used; some studies adopted a global assessment of the phenotype, whereas others dissected the phenotype into hypothetical components. The linkage method was either parametric model-based linkage analysis or nonparametric linkage analysis of allele sharing in affected relatives. DF, DeFries-Fulker regression analysis of selected sib-pairs; HE, Haseman-Elston regression analysis of sib-pairs; VC, variance-components analysis. *The report by Cardon et al. (1994), involving 50 twin pairs, included four pairs who were later discovered to be monozygotic. Re-analysis of the data excluding these four monozygotic twins led to a reduction in the significance of linkage and the results were published in a 1995 correction. The results given in this table are taken from the corrected report.

AUTOSOMAL DOMINANT Onetype of inheritancepattern that is observed for monogenic traits. Autosomes areany chromosomes in a cell that are not sex chromosomes. Autosomal dominant transmission results when an abnormal copy of an autosomal genefrom a single parent gives rise to thetrait, even though the copy inherited from the other parent isnormal. 'noise' across all chromosomes. For example, methods that are prone to yield false-positive evidence for linkage could be seen to yield equally high lod scores at numerous chromosomal sites.

Genome-wide scans have been carried out in two large extended pedigrees in which inheritance is consistent with AUTOSOMAL DOMINANT transmission ${ }^{41,42}$. Thefirst (from Norway) yielded significant linkage to 2p15-16, whereas the second (from Finland) strongly implicated 3p12-q13 (TABLE 4). Neither study reported linkage to sites that were indicated by previous investigations. In each family, although linkage evidence was convincing, phenotype-genotype correspondence was incomplete, with cases of phenocopy and/or non-penetrance ${ }^{41,42}$. Again, these molecular studies directly show the genetic complexity of dyslexia. Heterogeneity, reduced penetrance and phenocopies are evident, even when studying single multigenerational pedigrees with apparently simple inheritance. Furthermore, these kinds of family are scarce, raising the question of whether the rel evant genetic effects will general izeto thewider population of peoplewith dyslexia. To identify loci that areimportant for the latter, Fisher and colleague ${ }^{50}$ performed genome-wide scans in two large sets of nuclear families affected by dysl exia, from the United Kingdom and the United States, using QTL methodology and simulations to assess significance of the results. Previous targeted investigations of these family collections had provided evidence in support of the 6p21.3 locus $5^{33,34,37,51}$, which could now be assessed in the context of the remainder of the genome. The study continued to support the importance of $6 p 21.3$ in dyslexia, but indicated several other regions on various chromosomes that might similarly beinvolved in 


\begin{tabular}{|c|c|c|c|c|}
\hline Authors (year) & Sample (country) & $\begin{array}{l}\text { Treatment of } \\
\text { phenotype }\end{array}$ & Summary of findings & Reference \\
\hline $\begin{array}{l}\text { Fagerheim et al. } \\
\text { (1999) }\end{array}$ & $\begin{array}{l}1 \text { large extended } \\
\text { family with apparent } \\
\text { autosomal dominant } \\
\text { inheritance (Norway) }\end{array}$ & $\begin{array}{l}\text { Qualitative, } \\
\text { global }\end{array}$ & $\begin{array}{l}\text { - Genome-wide parametric analyses: significant linkage to } 2 \mathrm{p} 15-16 \text {; maximum } \\
\text { pointwise lod scores of } 2.92,3.54 \text { or } 4.32 \text {, depending on inclusion criteria } \\
\text { - Nonparametric analyses of } 2 \text { p15-16: multipoint P-values of } 0.016,0.023 \text { or } \\
0.0009 \text {, depending on inclusion criteria } \\
\text { - Co-segregation: of } 18 \text { genotyped family members with positive current } \\
\text { diagnosis and/or history of dyslexia, } 15 \text { were IBD for } 2 \text { p15-16 (i.e. } 3 \text { possible } \\
\text { cases of phenocopy); one child who inherited the } 2 p \text { risk genotype appeared } \\
\text { to be unaffected (potential case of non-penetrance) }\end{array}$ & 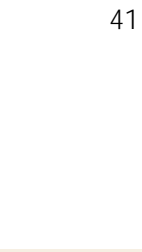 \\
\hline $\begin{array}{l}\text { Nopola-Hemmi } \\
\text { et al. }(2001)\end{array}$ & $\begin{array}{l}1 \text { large extended } \\
\text { family with apparent } \\
\text { autosomal dominant } \\
\text { inheritance (Finland) }\end{array}$ & $\begin{array}{l}\text { Qualitative, } \\
\text { global }\end{array}$ & $\begin{array}{l}\text { - Genome-wide nonparametric analyses in subset of family: most significant } \\
\text { result for } 3 p 12-q 13 \text { region, with } P=0.0017 \\
\text { - Follow-up nonparametric analyses of } 3 p 12-q 13 \text { in full extended family: } \\
P=0.00006 \\
\text { - Parametric analyses of 3p12-q13 in full extended family: significant multipoint } \\
\text { lod score of } 3.84 \\
\text { - Co-segregation: of } 21 \text { dyslexic members, } 19 \text { were IBD for } 3 p 12-q 13 \\
\text { (i.e. } 2 \text { cases of phenocopy); simulations showed that this would occur by } \\
\text { chance in <1/1,000 genome scans }\end{array}$ & 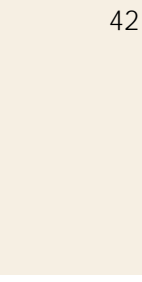 \\
\hline \multirow[t]{3}{*}{$\begin{array}{l}\text { Fisher et al. } \\
(2002)\end{array}$} & $\begin{array}{l}89 \text { nuclear families } \\
\text { (UK) }\end{array}$ & $\begin{array}{l}\text { Quantitative, } \\
\text { components }\end{array}$ & $\begin{array}{l}\text { - Genome-wide QTL analyses of phoneme awareness, phonological decoding, } \\
\text { orthographic processing, single-word reading: implicated several regions; } \\
\text { most significant results on chromosomes } 2,3,6,9,11,18 \text { and } X \text {; included } \\
2 \text { p16 and 3p13 regions close to those found in previous scans; region on } \\
18 \text { p11.2 gave empirical multipoint } P<0.00001 \text { with single-word reading } \\
\text { using VC approach }\end{array}$ & 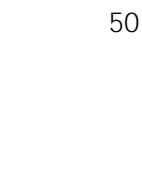 \\
\hline & $\begin{array}{l}119 \text { twin-based } \\
\text { families (USA) }\end{array}$ & $\begin{array}{l}\text { Quantitative, } \\
\text { components }\end{array}$ & $\begin{array}{l}\text { - Genome-wide QTL analyses of phoneme awareness, phonological decoding, } \\
\text { orthographic processing, single-word reading: implicated several regions; } \\
\text { most significant results on } 2,3,4,8,13,18 \text { and } 21 \text {; included } 2 \text { p15 and } 3 q 13 \\
\text { regions implicated by previous scans; region on } 18 p 11.2 \text { gave empirical } \\
\text { multipoint P }<0.0004 \text { with single-word reading using DF approach }\end{array}$ & \\
\hline & $\begin{array}{l}84 \text { nuclear families } \\
\text { (UK) }\end{array}$ & $\begin{array}{l}\text { Quantitative, } \\
\text { components }\end{array}$ & $\begin{array}{l}\text { - QTL analysis of 18p11.2 for component measures in independent data set: } \\
\text { replication of linkage; most significant empirical multipoint P }<0.0005 \text { for VC } \\
\text { analysis of phoneme awareness; combined analysis of all } 173 \text { UK families } \\
\text { confirmed that 18p11.2 influences multiple measures }\end{array}$ & \\
\hline
\end{tabular}

Qualitative affection status or quantitative measures of deficit were used; some studies adopted a global assessment of the phenotype, whereas others dissected the phenotype into hypothetical components. The linkage method was either parametric model-based linkage analysis or nonparametric linkage analysis of allele sharing in affected relatives. DF, DeFries-Fulker regression analysis of selected sib-pairs; IBD, identical-by-descent; QTL, quantitative trait locus; VC, variance-components analysis.

\author{
TRANSLOCATION \\ A genetic rearrangement in \\ which part of a chromosomeis \\ detached by breakage and \\ becomes attached to another \\ part of the samechromosome, \\ or to a different chromosome. \\ DUPLICATION \\ A genetic rearrangement that \\ involves the doubling or \\ repetition of part of a \\ chromosome. \\ DELETION \\ A genetic rearrangement that \\ involves the loss of part of a \\ chromosome \\ INVERSION \\ A genetic rearrangement in \\ which part of a chromosomeis \\ reversed, so that the genes within \\ that part arein inverse order. \\ BREAKPOINT \\ The specific site of chromosomal \\ breakage that is associated with a \\ particular chromosoma \\ rearrangement.
}

trait susceptibility (TABLE 4). Notably, both the UK and the U S samples implicated regions on 2p15-16 and 3p12-q13, indicating that effects at these loci might indeed be relevant to common forms of dyslexia, rather than being restricted to rare multigenerational pedigrees with simpler transmission ${ }^{50,71}$. This concordance is especially encouraging, given the disparity between the methods in the Norwegian/Finnish investigations and the UK/US genome scans. Furthermore, an independent study of Canadian families replicated the linkage at the $2 p$ locus with both qualitative and quantitative methods, strengthening the case that this represents a susceptibility locus ${ }^{72}$.

The key finding of the genome-wide searches by Fisher et al. ${ }^{50}$ was the observation of strong linkage to $18 p 11.2$ in the UK families. This same region was among the most significant results in the US sample, and also linked in a third independent set of families that were investigated. This study illustrates the value of QTL-based genome-wide scans in largesamples, detecting at least four potential dyslexia susceptibility loci (on chromosomes 2, 3, 6 and 18) for which thereis independent verification in multiple data sets. However, note that, as in all complex-trait analyses, until therelevant gene variants are pinpointed, therestill remains a possibility that oneor more of theseloci might turn out to represent false-positivefindings.
Alternative approaches to detecting dyslexia loci Linkage studies are complemented by the investigation of people with chromosomal abnormalities, such as TRANSLOCATIONS, DUPLICATIONS, DELETIONS Or INVERSIONS, that are associated with the trait of interest. For example, translocations might disrupt a geneat a breakage site or lead to the fusion of two normally unrelated genes; in some cases, this can betraced as the cause of the disorder. M any chromosomal alterations haveno phenotypic consequences or alter the expression of genes that map up to one million bases away from a BREAKPOINT (known as a position effect), so caution is needed when interpreting such data. Nopola-Hemmi et al. ${ }^{73}$ described two independent families in which people with dyslexia had inherited translocations that involved the same region of $15 q 21$, consistent with that previously implicated by linkage studies. In each family, therewere also children who were unaffected despite inheriting a rearrangement, indicating a significantly reduced penetrance. However, the convergence of independent linkage and translocation data provides further support for a $15 q$ locus influencing dyslexia, and detailed analysis of the translocations might aid in the isolation of the putativerisk gene. Another study reported co-segregation of a translocation involving $1 p 22$ and $2 q 31$ with retarded speech development and dyslexia in threemembers of a family ${ }^{39}$. However, the associated breakpoints map a 


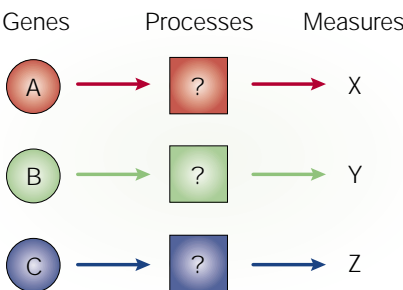

b

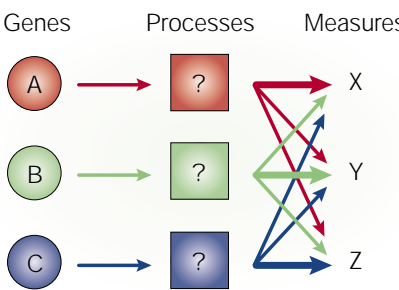

C Genes

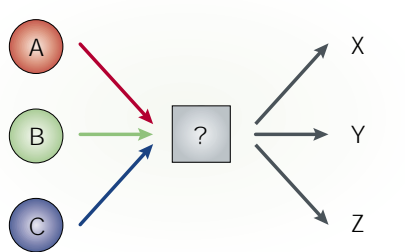

d

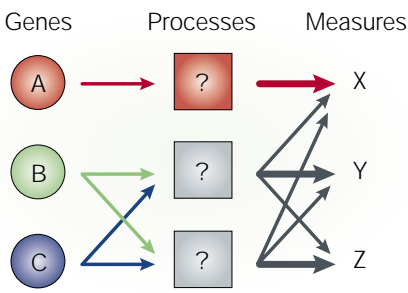

Figure 4 | Genetic dissection of dyslexia. Schematic simplified representations of pathways that map specific genes (A, B and C) to phenotypic measures of different aspects of reading ability ( $X, Y$ and $Z)$ through unknown neurological mechanisms (indicated by '?'). a | The simplest models involve straightforward one-to-one relationships between specific genes and different measures, implying the presence of unique underlying brain processes (shown in red, green and blue). Both genetic and psychometric data indicate that this is unlikely to be valid. $\mathbf{b} \mid \mathrm{A}$ more complex model acknowledges that, although the language- and reading-related measures that are used for the phenotypic assessment of dyslexia might tap predominantly one or other hypothetical component, they do not represent pure indicators of isolated brain processes. So, even if genes map to separable neurological mechanisms, simple relationships will not be revealed. c $\mid$ There are moderate to high correlations between most language- and readingrelated measures, and twin studies indicate that the correlated variance is highly heritable. So, it is possible that multiple genes influence common mechanisms that influence all measures. $\mathbf{d} \mid$ Twin studies also indicate the presence of heritable variability that is independent for each measure. It is therefore most likely that the underlying aetiology of dyslexia involves a complex interplay between specific and mixed effects. In reality, all these models are gross oversimplifications, as they ignore the role of the environment and the possibility of interactions between different genes or different neurological mechanisms. They are intended merely to illustrate some of the key issues for researchers seeking a genetic explanation of dyslexia.

LINKAGE DISEQUILIBRIUM Non-random association between specific allelic variants at one genetic locus and those at another genetic locus that maps nearby.

\section{EFFECT SIZE}

A standardized measure of effect that is adopted when different scales areused to measurean outcome. In QTL analyses, the effect size is the proportion of variability in a measurethat is attributable to the genetic locus of interest. substantial distance from regions of chromosomes 1 and 2 that are highlighted by other dyslexia studies; too far to be explained by position effects.

Another approach that is beginning to be applied to dyslexia is association analysis ${ }^{74}$. Whereas linkage assesses phenotype-genotype co-segregation within a family, association looks for correlations between specific alleles and a trait at the population level. Thelatter has greater power to detect genes of minor effect and allows risk variants to be mapped at higher resolution. Positiveevidence of association could indicate that the alleleitself is a risk variant, but can also be observed for alleles at loci that are in LINKAGE DISEQUILIBRIUM with the true susceptibility gene. So far, targeted association studies of dyslexia have been undertaken for small regions of $15 q$ (REF. 75), $2 q$ (REF. 71) and $6 p$ (REF. 76); it is not yet feasible to carry out studies of this type on a genome-wide scale. This is because association approaches require a much higher density of marker coverage than linkage methods to ensure the reliable detection of a genetic effect. Furthermore, theappropriate selection of markers is influenced by regionspecific patterns of linkage disequilibrium, which vary substantially throughout the genome $\mathrm{e}^{74}$.
A molecular genetic dissection of dyslexia? A recent idea that captured theimagination of many researchers wasthe proposal that different components of this complex phenotypecould be linked to distinct genetic loci ${ }^{35}$. The corollary is that molecular investigations might reveal simpleone-to-one mapping between certain cognitive processes and specific genevariants, which combineto give the overall dysl exic phenotype (FIG.4). The hope that the genetic aetiology of dyslexia could bethus dissected initially arose from analyses of chromosomes 6 and 15 by Grigorenko and colleagues ${ }^{35}$. After observing variable patterns of linkage for different component phenotypes at each locus, they suggested the possibility of separable genetic effects, such that phoneme awareness mapped to chromosome 6 , whereas single-word reading mapped to 15 . This interpretation has been criticized $30,36,37,77$. First, Grigorenko et al. identified significant linkage to $6 p$ with every phenotype under investigation ${ }^{37,77}$. M aximum lod scores at this locus varied for each component, with phoneme awareness highest and single-word reading lowest, but the differences in linkage evidence were not significant. Second, variability in the profiles of results at each locus might have resulted from the use of alternative statistical methodologies; linkage to chromosome 6 was observed only with nonparametric techniques, whereas linkageto chromosome 15 was found only by parametric analy$\mathrm{sis}^{37}$. Third, the validity of viewing single-word reading as a component phenotype, cognitively separatefrom phoneme awareness, has been questioned ${ }^{77}$.

Other studies have failed to support the idea that loci on 6 and 15 predominantly influence any singlecomponent ${ }^{37,40,50-52,65,73,76}$. For example, QTL-based sib-pair analyses consistently indicate that the $6 p$ locus affects several aspects of dyslexia, including phonological and orthographic processing and rapid naming ${ }^{37,50-52,76}$. M ost importantly, the authors of the Grigorenko et al. ${ }^{35}$ report carried out a follow-up study in an expanded sample, including new families and further subjects from the original pedigree ${ }^{65}$. In this later investigation, linkageto $6 p$ becamestrongest for single-word reading, and much weaker for phonemeawareness (that is, an inverse pattern to the initial findings). As the authors point out, this highlights one of the key methodological challenges that researchers in the field face ${ }^{65}$. Comparing magnitudes of univariatelinkagefor each component is not a reliableway of evaluating relative EFFECT SIZES of a particular locus on different aspects of the phenotype ${ }^{37,50,65}$. Linkage levels might beinfluenced by factors that are unrelated to the underlying genetic effect, such as age distribution of the sample, sensitivity of psychometric testing, or even simple stochastic variability resulting from inadequate samplesize $\mathrm{e}^{37,50,65}$. It has also been shown that the process of maximizing lod scores in a particular data set leads to a bias in estimating effect size, which can beparticularly problematic when evaluating data from genome-wide scans ${ }^{78}$.

These concerns are further illustrated by the identification of a potential susceptibility locus on chromosome 18 in two separate QTL-based genome-wide scan $5^{50}$. In the UK scan sample of Fisher et al..$^{50}$, there 
B ox 3 | A gene mutated in a speech and language disorder

Although the boundaries between speech/language disorders and dyslexia are not always clear, the former involve gross language problems, detected by standard tests of grammar, syntax and/or vocabulary ${ }^{31}$. Peoplewith dyslexia often perform in thenormal range on these tests, but show deficits in language-related processes such as the manipulation of phonemes. In 1998, Fisher et al ${ }^{58}$ reported linkage studies of a unique threegeneration family, known as KE, in which severe speech and language impairment was inherited as an autosomal dominant monogenic trait. Using traditional approaches, the locus was mapped to a small interval of 7q31, which co-segregated perfectly with the disorder; that is, there was $100 \%$ concordance between genotype and affection status, with no phenocopies and full penetrance.

The researchers constructed a sequence-based map of genes in 7q31, and used it to direct mutation analyses ${ }^{80}$. The search was aided by theidentification of CS, an unrelated child with similar problems to those of family KE, which were associated with a translocation involving 7q31. Localization of the translocation breakpoint indicated that it disrupted the geneencoding FOXP2, a transcription factor containing a forkhead/winged-helix D NA-binding domain ${ }^{81}$. FOXP2 belongs to a family of proteins that are key regulators of gene expression during embryogenesis, and have been implicated in various developmental disorders in humans and mice ${ }^{99-93}$. Sequencing of FOXP2 in the KE family revealed a point mutation in all affected individuals, altering an amino-acid residue in a crucial part of the DNA-binding domain of the protein ${ }^{81}$.

The phenotype associated with FOXP2 disruption is severe, involving difficulty in controlling the finemouth movements that are required for speech ${ }^{94}$, coupled with deficits in many aspects of language processing and grammatical skill ${ }^{95}$. Some individuals in the KE family have reduced non-verbal intelligence ${ }^{95}$, but thesegeneral cognitive deficits do not tend to co-segregate with the disorder. Variants in the coding region of FOXP2 do not seem to bea main cause of morecommon forms of speech and language impairment ${ }^{22}$. However, functional studies of FOXP2 might offer new insight into neurological mechanisms that are important for an individual to acquire speech and language ${ }^{6,97}$.

TRANSCRIPTION FACTOR A DNA-binding protein that regulates geneexpression. was strong linkage of 18p11.2 to single-word reading, but substantially weaker evidence for other measures. Taken at face value and disregarding the issues discussed above, it might be reasonable to conclude that this locus is 'specific' to single-word reading. However, analysis of the US sampleindicated morewide ranging effects of 18p11.2 on multiple measures. A further independent sample of UK families was specifically investigated at 18p11.2, and linkage was replicated, but in this case, the most significant evidence arosefrom a measure of phonemeawareness ${ }^{50}$. Combined analyses of all UK families supported the view that the 18p locusisa general risk factor for dyslexia. Observed differences in linkage profiles probably arose from stochastic variability owing to small sample sizes, along with the effect-size biases associated with genome scanning ${ }^{50,78}$.

It is clear from heritability and linkage studies that simple relationships between hypothetical components of the reading process and molecular genetic data are unlikely to exist (FIG.4). H owever, there is still considerable interest in the possibility of the 'genetic dissection' of dyslexia. As discussed above, attempts to address this through univariate analyses have been ineffectual, and approaches are needed that can accurately estimaterelative effect sizes of a particular locus for different reading- and language-related measures. Bivariatelinkage analyses are al ready being carried out ${ }^{52,79}$, but perhaps the most promise lies with fully multivariate linkage methods that can simultaneously incorporate data from all measures. However, for a comprehensive dissection of the genetic aetiology of dyslexia, wewill first need to find the risk genes themselves, and to examine their effects in very large samples.

Can we identify susceptibility genes for dyslexia? Although theconcordance of linkage resultsisencouraging, finding the particular genetic variants that influence dyslexia remainsa daunting task. Linkagetypically implicates chromosomal regions that contain hundreds of candidate genes, so success will probably depend on complementary data from chromosomal abnormalities and/or association-based analyses, as well as the use of much larger sample sizes - thousands, rather than hundreds, of nuclear families. The availability of comprehensive data from human genomic sequencing projects will have a great impact on these efforts ${ }^{31}$. So far, no specific dyslexia risk gene has been identified, but studies of speech and language deficits have been morefruitful, yielding a gene responsible for a rare and severeform of the disorder $58,80,81$ (BOX 3). This serves as a pertinent example of how investigations of these types of trait might ultimately succeed and yield new insight into underlying processes. Themain caveat is that genetic effects that are implicated in rare cases might not necessarily explain variability in thewider population ${ }^{82}$.

Identification of specific gene variants that contribute to dyslexia will have many ramification ${ }^{30}$. These include the possibility of early identification of those at elevated risk, allowing environmental intervention at a young age and the diagnosis of phenotypically ambiguous cases. Notethat genotype- phenotype correspondence will usually befar from perfect, so any predictions will be probabilistic (concordance rates of reading difficulties in $M Z$ twins areonly $\sim 2 / 3$ ). A main goal after identifying crucial genes will beto increase our understanding of the molecular pathology of dyslexia, with the hope that this will also shed light on the mechanisms that are involved in normal readingand language related processes. Even if a gene is only implicated in arare form of the trait, it will still provide a valuable entry point into the relevant developmental pathways ${ }^{31}$. The nature of functional studies will depend largely on the types of protein that the genes encode, be they involved in metabolism, structure, signalling, transcriptional regulation or some other cellular process ${ }^{83}$. For example, if a susceptibility gene is found to encodea cell-surface receptor, then a variety of techniques can be used to isolate the proteins with which it interacts and to dissect the relevant signalling pathways. Alternatively, for a susceptibility gene that encodes a TRANSCRIPTION FACTOR, it is possible to exploit new methods to identify the downstream targets in neuronal development. I solation of key genetic pathways that are implicated in reading- and languagerelated disorders might help to bridgethe gaps between other levels of study, such as brain imaging and neuropsychology, bringing us closer to a comprehensive explanation of the aetiology of dyslexia. 
1. Hinshelwood, J. Word blindness and visual memories. Lancet 2, 1566-1570 (1895).

2. Morgan, W. P. A case of congenital word blindness Br. Med. J . 2, 1378 (1896)

3. Orton, S. T. Word-blindness in school children. Arch. Neurol. Psychiatr. 14, 582-615 (1925).

4. Snowling, M. J. From language to reading and dyslexia. Dyslexia 7, 37-46 (2001).

5. Wolf, M. \& Bowers, P. G. Naming-speed processes and developmental reading disabilities: an introduction to the special issue on the double-deficit hypothesis. J. Learn. Disabil. 33, 322-324 (2000)

6. Eden, G. F. et al. Abnormal processing of visual motion in dyslexia revealed by functional brain imaging. Nature 382 66-69 (1996).

7. Temple, E. et al. Disruption of the neural response to rapid acoustic stimuli in dyslexia: evidence from functional MRI. Proc. Natl Acad. Sci. USA 97, 13907-13912 (2000).

8. Nicolson, R. I., Fawcett, A. J \& \& Dean, P. Developmental dyslexia: the cerebellar deficit hypothesis. Trends Neurosci. 24, 508-511 (2001).

9. Stein, J \& W Walsh, V. To see but not to read; the magnocellular theory of dyslexia. Trends Neurosci. 20 147-152 (1997).

10. Hari, R. \& Renvall, H. Impaired processing of rapid stimulus sequences in dyslexia. Trends Cogn. Sci. 5, 525-532 (2001).

11. Habib, M. The neurological basis of developmental dyslexia. An overview and working hypothesis. Brain $\mathbf{1 2 3}$ 2373-2399 (2000). A comprehensive discussion of multidisciplinary investigations into the aetiology of dyslexia.

12. Thomas, C. J. Congenital 'word-blindness' and its treatment. Ophthalmoscope 3, 380-385 (1905).

13. Stephenson, S. Six cases of congenital word-blindness affecting three generations of one family. Ophthalmoscope 5, 482-484 (1907).

14. Hallgren, B. Specific dyslexia ('congenital word blindness'): a clinical and genetic study. Acta Psychiatr. Neurol. Scand. 65 (Suppl.), 1-287 (1950).

15. Finucci, J. M., Guthrie, J. T., Childs, A. L., Abbey, H. \& Childs, $B$. The genetics of specific reading disability. Ann Hum. Genet. 40, 1-23 (1976).

16. Lewitter, F. I., DeFries, J . C. \&Elston, R. C. Genetic models of reading disabilities. Behav. Genet. 10, 9-30 (1980).

17. Vogler, G. P., DeFries, J.C. \& Decker, S. N. Family history as an indicator of risk for reading disability. J . Learn. Disabil. 18 419-421 (1985).

18. Pennington, B. F. et al. Evidence for major gene transmission of developmental dyslexia. J AMA 266 transmission of dever

19. Wolf, P. H.\& Melngailis, I. Family patterns of developmental dyslexia: clinical findings. Am. J. Med. Genet. 54, 122-131 (1994)

20. Bakwin, H. Reading disability in twins. Dev. Med. Child Neurol. 15, 184-187 (1973).

21. Stevenson, J ., Graham, P., Fredman, G. \& McLoughlin, V. A twin study of genetic influences on reading and spelling ability and disability. J. Child Psychol. Psychiatry $\mathbf{2 8}$ 229-247 (1987).

22. DeFries, J . C., Fulker, D. W. \& LaBuda, M. C. Evidence for a genetic aetiology in reading disability of twins. Nature $\mathbf{3 2 9}$, 537-539 (1987).

23. DeFries, J.C. \& Alarcón, M. Genetics of specific reading disability. Ment. Retard. Dev. Disabil. Res. Rev. 2, 39-47 (1996).

24. Pennington, B. F. \& Lefly, D. L. Early reading development in children at family risk for dyslexia. Child Dev. 72, 816-833 (2001)

25. DeFries, J . C. \& Fulker, D. W. Multiple regression analysis of twin data. Behav. Genet. 15, 467-473 (1985).

26. DeFries, J. C. \& Gillis, J . J in Nature, Nurture, and Psychology (eds Plomin, R. \& McClearn, G.) 121-145 (American Psychiatric Association, Washington DC, 1993).

27. Gayán, J \& \& Olson, R. K. Genetic and environmental influences on orthographic and phonological skills in children with reading disabilities. Dev. Neuropsychol. 20, 483-507 (2001).

28. Bishop, D. V. M. et al. Different origin of auditory and phonological processing problems in children with language impairment: evidence from a twin study. J. Speech Lang. Hear. Res. 42, 155-168 (1999)

29. Stevenson, J. Evidence for a genetic etiology in hyperactivity in children. Behav. Genet. 22, 337-344 (1992)

30. Fisher, S. E. \& Smith, S. D. in Dyslexia: Theory and Good Practice (ed. Fawcett A J ) 39-64 (Whurr, London, UK, 2001).

31. Fisher, S. E. in Behavioral Genetics in the Postgenomic Era (eds Plomin, R., DeFries, J. C., Craig, I. W. \& MCGuffin, P.) 205-226 (American Psychiatric Association, Washington DC, 2002).
32. Smith, S. D., Kimberling, W. J. Pennington, B. F. \& Lubs, H. A. Specific reading disability: identification of an inherited form through linkage analysis. Science 219, 1345 (1983).

33. Cardon, L. R. et al. Quantitative trait locus for reading disability on chromosome 6. Science 266, 276-279 (1994). An early demonstration of the value of applying QTL mapping methods to continuous measures of cognitive ability. Strong evidence was provided for a locus on $6 p$, which was subsequently verified in several independent populations.

34. Cardon, L. R. et al. Quantitative trait locus for reading disability: correction. Science 268, 1553 (1995).

35. Grigorenko, E. L. et al. Susceptibility loci for distinct components of developmental dyslexia on chromosomes 6 and 15. Am. J . Hum. Genet. 60, 27-39 (1997). This paper proposed the intriguing idea that differing aspects of the dyslexia profile might link to distinct genetic loci. Although some conclusions from this study have been criticized, it raised the key question of whether we can reliably dissect complex cognitive phenotypes using genetic linkage data.

36. Field, L. L. \& Kaplan, B. J . Absence of linkage of phonological coding dyslexia to chromosome 6p23-p21.3 in a large family data set. Am. J . Hum. Genet. 63 1448-1456 (1998).

37. Fisher, S. E. et al. A quantitative trait locus on chromosome $6 p$ influences different aspects of developmental dyslexia. Am. J. Hum. Genet. 64, 146-156 (1999)

38. Bisgaard, M. L., Eiberg, H., Moller, N., Niebuhr, E. \& Mohr, J. Dyslexia and chromosome 15 heteromorphism: negative lod score in a Danish sample. Clin. Genet. 32, 118-119 (1987).

39. Froster, U., Schulte-Körne, G., Hebebrand, J . \& Remschmidt, H. Cosegregation of balanced translocation $(1 ; 2)$ with retarded speech development and dyslexia. Lancet 342, 178-179 (1993).

40. Schulte-Körne, G. et al. Evidence for linkage of spelling disability to chromosome 15. Am. J. Hum. Genet. 63 , 279-282 (1998).

41. Fagerheim, T. et al. A new gene (DYX3) for dyslexia is located on chromosome 2. J. Med. Genet. 36, 664-669 (1999).

The successful genome-wide application of traditional parametric methods led to the localization of a dyslexia risk gene in a single large pedigree.

42. Nopola-Hemmi, J . et al. A dominant gene for developmenta dyslexia on chromosome 3. J. Med. Genet. 38, 658-664 (2001).

\section{A genome-wide study of a large extended family} identified a susceptibility locus for dyslexia on chromosome 3 . References 41 and 42 provide a clear example of genetic heterogeneity, even when investigating multigenerational pedigrees.

43. Castles, A. \& Coltheart, M. Varieties of developmental dyslexia. Cognition 47, 149-180 (1993).

44. Castles, A., Datta, H., Gayán, J . \& Olson, R. K. Varieties of developmental reading disorder: genetic and environmental influences. J . Exp. Child Psychol. 72, 73-94 (1999).

45. Lander, E. S. \& Schork, N. J. Genetic dissection of complex traits. Science 265, 2037-2048 (1994) An excellent introduction to key concepts of complex genetic analysis.

46. Haseman, J. K. \& Elston, R. C. The investigation of linkage between a quantitative trait and a marker locus. Behav. Genet. 2, 3-19 (1972)

47. Cardon, L. R. \& Fulker, D. W. The power of interval mapping of quantitative trait loci, using selected sib pairs. Am. J. Hum. Genet. 55, 825-833 (1994)

48. Amos, C. I. Robust variance-components approach for assessing genetic linkage in pedigrees. Am. J . Hum. Genet. 54, 535-543 (1994).

49. Allison, D. B. et al. Testing the robustness of the likelihood ratio test in a variance-component quantitative-trait locimapping procedure. Am. J. Hum. Genet. 65, 531-544 (1999).

50. Fisher, S. E. et al. Independent genome-wide scans identify a chromosome 18 quantitative-trait locus influencing dyslexia. Nature Genet. 30, 86-91 (2002). This paper reported the first QTL-based genome-wide linkage scans for dyslexia, yielding robust evidence for a chromosome 18 locus influencing dyslexia in three independent samples of sib-pairs, and implicating a number of other potential loci of interest.

51. Gayán, J. et al. Quantitative trait locus for specific language and reading deficits on chromosome $6 \mathrm{p}$. Am. J. Hum. Genet. 64, 157-164 (1999).

52. Davis, C. J . et al. Etiology of reading difficulties and rapid naming: the Colorado Twin Study of Reading Disability. Behav. Genet. 31, 625-635 (2001).

53. Wijsman, E. M. et al. Segregation analysis of phenotypic components of learning disabilities. I. Nonword memory and digit span. Am. J . Hum. Genet. 67, 631-646 (2000).
54. Raskind, W. H., Hsu, L., Berninger, V. W., Thomson, J. B. \& Wijsman, E. M. Familial aggregation of dyslexia phenotypes. Behav. Genet. 30, 385-396 (2000)

55. Marlow, A. J. et al. Investigation of quantitative measures related to reading disability in a large sample of sib-pairs from the UK. Behav. Genet. 31, 219-230 (2001).

56. Fisher, S. E., Stein, J . F. \& Monaco, A. P. A genome-wide search strategy for identifying quantitative trait loci involved in reading and spelling disability (developmental dyslexia). Eur. Child Adolesc. Psychiatry 8 (Suppl. 3), 47-51 (1999).

57. Kruglyak, L. \& Lander, E. S. Complete multipoint sib-pair analysis of qualitative and quantitative traits. Am. J. Hum Genet. 57, $439-454$ (1995).

58. Fisher, S. E., Vargha-Khadem, F., Watkins, K. E., Monaco, A. P. \& Pembrey, M. E. Localisation of a gene implicated in severe speech and language disorder. Nature Genet. 18, 168-170 (1998).

59. The SLI consortium. A genomewide scan identifies two novel loci involved in specific language impairment. Am. J. Hum. Genet. 70, 384-398 (2002).

60. Lander, E. \& Kruglyak, L. Genetic dissection of complex traits: guidelines for interpreting and reporting linkage results. Nature Genet. 11, 241-247 (1995). A technical overview of central concerns in the sound interpretation of linkage data when analysing complex traits.

61. Altmüller, J ., Palmer, L. J ., Fischer, G., Scherb, H. \& Wjst, M. Genomewide scans of complex human diseases: true linkage is hard to find. Am. J. Hum. Genet. 69, 936-950 (2001)

62. Rabin, M. et al. Suggestive linkage of developmental dyslexia to chromosome 1p34-p36. Lancet 342, 178 (1993).

63. Smith, S. D., Kimberling, W. J \& \& Pennington, B. F. Screening for multiple genes influencing dyslexia. Read. Writ. 3, 285-298 (1991)

64. Fulker, D. W. et al. Multiple regression of sib-pair data on reading to detect quantitative trait loci. Read. Writ. 3 299-313 (1991).

65. Grigorenko, E. L., Wood, F. B., Meyer, M. S. \& Pauls, D. L. Chromosome $6 \mathrm{p}$ influences on different dyslexia-related cognitive processes: further confirmation. Am. J . Hum. Genet. 66, 715-723 (2000).

66. Geschwind, N. \& Behan, P. Left-handedness: association with immune disease, migraine, and developmental learning disorder. Proc. Natl Acad. Sci. USA 79, 5097-5100 (1982).

67. Gilger, J. W. et al. A twin and family study of the association between immune system dysfunction and dyslexia using blood serum immunoassay and survey data. Brain Cogn. 36, 310-333 (1998)

68. Petryshen, T. L., Kaplan, B. J ., Liu, M. F. \& Field, L. L. Absence of significant linkage between phonological coding dyslexia and chromosome $6 \mathrm{p} 23-21.3$, as determined by use of quantitative-trait methods: confirmation of qualitative analyses. Am. J. Hum. Genet. 66, 708-714 (2000).

69. Grigorenko E. L. et al. Linkage studies suggest a possible locus for developmental dyslexia on chromosome $1 \mathrm{p}$. Am. . Med. Genet. 105, 120-129 (2001)

70. Petryshen T. L. et al. Evidence for a susceptibility locus on chromosome $6 \mathrm{q}$ influencing phonological coding dyslexia. Am. J. Med. Genet. 105, 507-517 (2001).

71. Francks, C. et al. Quantitative association analysis within the chromosome 2p12-16 dyslexia susceptibility region: microsatellite markers and candidate genes SEMA4F and OTX1. Psychiatr. Genet. 12, 35-41 (2002).

72. Petryshen, T. L., Kaplan, B. J ., Hughes, M. L., Tzenova, J \& Field, L. L. Supportive evidence for the DYX3 dyslexia susceptibility gene in Canadian families. J . Med. Genet. 39 125-126 (2002).

73. Nopola-Hemmi, J et al. Two translocations of chromosome 15q associated with dyslexia. J . Med. Genet. 37, 771-775 (2000).

74. Cardon, L. R. \& Bell, J . I. Association study designs for complex diseases. Nature Rev. Genet. 2, 91-99 (2001).

75. Morris, D. W. et al. Family-based association mapping provides evidence for a gene for reading disability on provides evidence for a gene for reading disability on
chromosome 15q. Hum. Mol. Genet. 9, 843-848 (2000). Converging evidence for a locus on $15 q$ has been revealed by complementary approaches to linkage mapping, including this report of association and a study of chromosomal abnormalities (reference 73).

76. Kaplan, D. E. et al. Evidence for linkage and association with reading disability on 6p21.3-22. Am. J . Hum. Genet. 70, 1287-1298 (2002).

77. Pennington, B. F. Using genetics to dissect cognition. Am. J Hum. Genet. 60, 13-16 (1997)

An insightful critique of the suggestion that genes might show simple mapping to individual cognitive processes that underlie dyslexia. 
78. Goring, H. H., Terwilliger, J . D. \& Blangero, J . Large upward bias in estimation of locus-specific effects from genomewide scans. Am. J . Hum. Genet. 69, 1357-1369 (2001).

79. Willcutt, E. G. et al. Quantitative trait locus for reading disability on chromosome $6 \mathrm{p}$ is pleiotropic for attentiondeficit/hyperactivity disorder. Am. J . Med. Genet. 114, 260-268 (2002)

80. Lai, C. S. L. et al. The SPCH1 region on human $7 q 31$ genomic characterization of the critical interval and localization of translocations associated with speech and language disorder. Am. J. Hum. Genet. 67, 357-368 (2000).

81. Lai, C. S. L., Fisher, S. E., Hurst, J . A., Vargha-Khadem, F. \& Monaco, A. P. A forkhead-domain gene is mutated in a severe speech and language disorder. Nature 413, 519-523 (2001).

This paper reports the identification of the FOXP2 gene and shows that its disruption causes one form of speech and language impairment. This is the only known case of a direct link between a specific gen and this type of developmental disorder.

82. Newbury, D. F. et al. FOXP2 is not a major susceptibility gene for autism or Specific Language Impairment (SLI). Am. J. Hum. Genet. 70, 1318-1327 (2002)

83. Nokelainen, P. \& Flint, J. Genetic effects on human cognition: lessons from the study of mental retardation syndromes. J . Neurol. Neurosurg. Psychiatry 72, 287-296 (2002)

84. Thomson, M. E. The assessment of children with specific reading disabilities (dyslexia) using the British Ability Scales. Br. J . Psychiatry 73, 461-478 (1982).

85. Siegel, L. S. \& Himel, N. Socioeconomic status, age and the classification of dyslexics and poor readers: the dangers of using IQ scores in the definition of reading disability. Dyslexia 4, 90-103 (1998).

86. Pennington, B. F., Gilger, J . W., Olson, R. K. \& DeFries, J . C. The external validity of age- versus IQ-discrepancy definitions of reading disability: lessons from a twin study. Lem. Disabil 25, 562-573 (1992)

87. Shapiro, B. K. Specific reading disability: a multiplanar view. Ment. Retard. Dev. Disabil. Res. Rev. 7, 13-20 (2001).

88. Shaywit, S. E. et al. Persistence of dyslexia: the Connecticut Longitudinal Study at adolescence. Pediatric 104, 1351-1359 (1999).

89. Nehls, M., Pfeifer, D., Schorpp, M., Hedrich, H. \& Boehm, T. New member of the winged-helix protein family disrupted in mouse and rat nude mutations. Nature 372, 103-107 (1994)

90. Nishimura, D. Y. et al. The forkhead transcription factor gene FKHL7 is responsible for glaucoma phenotypes which map FKHL7 is responsible for glaucoma phenotypes

91. Fang, J et al. Mutations in FOXC2 (MFH-1), a forkhead family transcription factor, are responsible for the hereditary lymphedema-distichiasis syndrome. Am. J . Hum. Genet. 67, 1382-1388 (2000).

92. Brunkow, M. E. et al. Disruption of a new forkhead/winged helix protein, scurfin, results in the fatal lymphoproliferative disorder of the scurfy mouse. Nature Genet. 27, 68-73 (2001).

93. Crisponi, L. et al. The putative forkhead transcription factor FOXL2 is mutated in blepharophimosis/ptosis/epicanthus inversus syndrome. Nature Genet. 27, 159-166 (2001)

94. Hurst, J. A., Baraitser, M., Auger, E., Graham, F. \& Norell, S. An extended family with a dominantly inherited speech disorder. Dev. Med. Child Neurol. 32, 347-355 (1990).

95. Vargha-Khadem, F., Watkins, K., Alcock, K., Fletcher, P. \& Passingham, R. Praxic and nonverbal cognitive deficits in large family with a genetically transmitted speech and language disorder. Proc. Natl Acad. Sci. USA 92, 930-933 (1995).

96. Bishop, D. V. M. Putting language genes in perspective. Trends Genet. 18, 57-59 (2002).

An interesting discussion of what the discovery of An interesting discussion of what the discovery of FOXP2 might tell
97. Fisher S. E. in Neurosciences at the Postgenomic Era (eds Mallet, J . \& Christen, Y.) (Springer-Verlag, Heidelberg, Germany, 2002).

Acknowledgements

S.E.F. is a Royal Society Research Fellow. J.C.D. is supported by a centre grant from the National Institute of Child Health and Human Development.

\section{(a) Online links}

\section{DATABASES}

The following terms in this article are linked online to:

LocusLink: http://www.ncbi.nlm.nih.gov/LocusLink/

FOXP2

OMIM: http://www.ncbi.nlm.nih.gov/Omim/

ADHD | dyslexia

OMIM Gene Map:

http://www.ncbi.nlm.nih.gov/Omim/searchmap.htm 1p22 | 1p34-36 | 2p15-16 | 2q31 |3p12-q13 |6p21.3 |6q12 |

$15 q 21$ | $18 p 11.2$

\section{EURTHER INFORMATION}

Encyclopedia of Life Sciences: http://www.els.net/ anguage | quantitative genetics

OXP2 in Speech and Language Disorder

http://www.well.ox.ac.uk/monaco/spchlcecilia.shtm Genetics of Developmental Dyslexia:

http://www.well.ox.ac.uk/monaco/dyslexiasimon.shtml Genetics of Specific Language Impairment: http://www.well.ox.ac.uk/monaco/dianne/index.shtml MIT Encyclopedia of Cognitive Sciences:

http://cognet.mit.edu/MITECS/

dyslexia | language impairment, developmental | reading | visual word recognition

Access to this interactive links box is free online. 